\title{
Menthol Cigarettes, Time to First Cigarette, and Smoking Cessation *
}

\author{
by \\ Edward Sanders ${ }^{1}$, Rolf Weitkunat ${ }^{2}$, and Ruth Dempsey ${ }^{2}$ \\ ${ }^{1}$ Edward Sanders Scientific Consulting, Peseux, Switzerland \\ ${ }^{2}$ Philip Morris Products SA, Philip Morris International, Research \& Development, Neuchâtel, Switzerland
}

\section{SUMMARY}

The goal of the present work is to determine if menthol and non-menthol cigarette smokers differ with respect to time to first cigarette (TTFC) and successful smoking cessation via a meta-analysis of published results. For 13 independent estimates, menthol smokers were slightly but statistically significantly more likely to exhibit TTFC $\leq 5 \mathrm{~min}$ (random-effects odds ratio $(\mathrm{OR})=1.12 ; 95 \%$ confidence interval (CI), 1.04-1.21), while 17 independent estimates provided a non-significant difference for TTFC $\leq 30 \mathrm{~min}$ (random-effects OR $=1.06 ; 95 \% \mathrm{CI}, 0.96-1.16$ ). For cessation studies, meta-analysis of 30 published estimates indicated a decreased likelihood for menthol cigarette smokers to quit (random-effects OR $=0.87 ; 95 \% \mathrm{CI}$, $0.80-0.96$ ). There was no difference between cessation rates for Caucasian menthol and non-menthol cigarette smokers, but the results support that African American menthol cigarette smokers find it more difficult to quit. Adjustment of cessation for socioeconomic status eliminated any statistically significant advantage for smoking cessation in non-menthol smokers. In conclusion, these results suggest that the observed differences in cessation rates between menthol and non-menthol cigarette smokers are likely explained by differences in socioeconomic status and also suggest that TTFC may not be a robust predictor of successful smoking cessation. [Beitr. Tabakforsch. Int. 27 (2017) 4-32]
KEYWORDS: Smoking cessation; time to first cigarette; menthol; socioeconomic status

\section{ZUSAMMENFASSUNG}

Ziel der vorliegenden Meta-Analyse veröffentlichter Ergebnisse ist es, zu bestimmen, ob sich Raucher von mentholhaltigen bzw. -freien Zigaretten hinsichtlich der morgendlichen Zeit bis zur ersten Zigarette (TTFC) sowie hinsichtlich der erfolgreichen Beendigung des Rauchens unterscheiden. Bei Rauchern von mentholhaltigen Zigaretten fand sich eine statistisch signifikante, leicht erhöhte Wahrscheinlichkeit für TTFC $\leq 5$ min (Zufallseffekt Odds Ratio $(\mathrm{ZE}-\mathrm{OR})=1.12 ; 95 \%$ Konfidenzintervall $(\mathrm{KI})$, 1.04-1.21) auf der Basis von 13 unabhängigen Schätzungen, wohingegen sich auf der Basis von 17 unabhängigen Schätzungen ein nicht-signifikanter Unterschied für $\mathrm{TTFC} \leq 30$ min ergab (ZE-OR = 1.06; 95\% KI, 0.96-1.16). Dreißig veröffentlichte Schätzungen aus Rauchentwöhnungsstudien deuten auf einen reduzierten Erfolg bei Rauchern von mentholhaltigen Zigaretten hin (ZE-OR $=0.87 ; 95 \% \mathrm{KI}$, 0.80-0.96). Während sich bei Kaukasiern kein Unterschied in der erfolgreichen Rauchentwöhnung zwischen Rauchern von Zigaretten mit bzw. ohne Menthol zeigte, schienen afroamerikanische Raucher größere Schwierigkeiten mit erfolgreicher Rauchentwöhnung zu haben, wenn sie mentholhaltige Zigaretten rauchten. Die Bereinigung der Entwöhnungsraten um den Einfluss des sozioökonomischen

*Received: $09^{\text {th }}$ August 2016 - accepted: $25^{\text {th }}$ October 2016 
Status eliminierte alle statistisch signifikanten Vorteile von Rauchern mentholfreier Zigaretten. Insgesamt deuten die Ergebnisse darauf hin, dass die beobachteten Unterschiede in den Entwöhnungsraten zwischen Rauchern von Zigaretten mit bzw. ohne Menthol auf Unterschiede im sozioökonomischen Status zurückzuführen sind. Dies weist darauf hin, dass TTFC möglicherweise kein robuster Prädiktor für erfolgreiche Rauchentwöhnung ist. [Beitr. Tabakforsch. Int. 27 (2017) 4-32]

\section{RESUME}

Le but du présent travail est de déterminer, grâce à une méta-analyse de résultats publiés, si le temps de latence avant la première cigarette ("time to first cigarette", TTFC) ainsi que la capacité à arrêter de fumer diffèrent entre fumeurs de cigarettes mentholées et non-mentholées. Treize des estimations indépendantes montrent que les fumeurs de ciagrettes mentholées sont légèrement, mais de manière statistiquement significative, plus susceptibles de présenter $\mathrm{TTFC} \leq 5$ minutes (effets aléatoires odds ratio $(\mathrm{OR})=1.12$; intervalle de confiance (IC) 95\%, 1.04 à 1.21), alors que 17 estimations indépendantes rapportent une différence non significative pour TTFC $\leq 30$ minutes (effets aléatoires $\mathrm{OR}=1.06$; IC $95 \%, 0.96$ à 1.16). En ce qui concerne les études de sevrage tabagique, la méta-analyse des 30 estimations publiées indique que les fumeurs de cigarettes mentholées ont une probabilité plus faible d'arrêter de fumer (effets aléatoires $\mathrm{OR}=0.87$; IC 95\%, 0.87 à 0.96). Il n'y a pas de différence entre les taux de sevrage des caucasiens fumeurs de cigarettes mentholées et ceux des fumeurs de cigarettes non-mentholées, mais les résultats soutiennent que les afro américains fumeurs de cigarettes mentholées trouvent qu'il est plus difficile de cesser. L'ajustement du taux de sevrage en fonction du statut socio-économique élimine tout avantage statistiquement significatif du sevrage tabagique chez les fumeurs de cigarettes non-mentholées. En conclusion, ces résultats suggèrent que les différences observées entre les taux de sevrage de fumeurs de cigarettes mentholées et nonmentholées peuvent s'expliquer par des différences de statut socio-économique. Ces résultats suggèrent également que TTFC peut ne pas être un prédicateur robuste de la capacité de cesser de fumer. [Beitr. Tabakforsch. Int. 27 (2017) 4-32]

\section{ABBREVIATIONS}

$\begin{array}{ll}\text { CI } & \text { Confidence interval } \\ \text { CPD } & \text { Cigarettes per day } \\ \text { CPS } & \text { Current population survey } \\ \text { FDA } & \text { Food and Drug Administration } \\ \text { FTND } & \text { Fagerström Test for Nicotine Dependence } \\ \text { GED } & \text { General education development } \\ \text { HSI } & \text { Heaviness of smoking index } \\ \text { I }^{2} & \text { Index of heterogeneity-attributable } \\ \text { variance percent } & \text { National health and nutrition examination } \\ \text { NHANES } & \begin{array}{l}\text { survey } \\ \text { National health interview survey - cancer }\end{array}\end{array}$

$\begin{array}{ll}\text { NSDUH } & \text { control supplement } \\ \mathrm{OR} & \text { National survey on drug use and health } \\ \mathrm{p} & \text { Odds ratio } \\ \text { RCT } & \text { Probability value } \\ \mathrm{SES} & \text { Randomized controlled trial } \\ \text { TTFC } & \text { Socioeconomic status } \\ \text { TUS } & \text { Time to first cigarette } \\ \text { TUS-CPS } & \text { Tobacco use supplement } \\ & \text { Tobacco use supplement - current } \\ & \text { population survey }\end{array}$

\section{INTRODUCTION}

The considerable negative impact of cigarette smoking on individual and public health (1) and the benefits of smoking cessation (2) have been conclusively established for many years. As a consequence, identification of a particular type of cigarette for which either dependence is increased or for which cessation would be more difficult would be of particular public health interest. One type of cigarette product that is currently receiving some attention in many parts of the world including the US with respect to these two issues is the mentholated cigarette. It has been suggested that menthol in cigarette smoke may reduce the irritation and harshness of smoking thus altering smoking topography and leading to inhalation of greater amounts of nicotine. Increased nicotine exposure could in turn lead to increased dependence and possibly a greater difficulty of menthol cigarette smokers to quit (3).

This publication reports the results of a meta-analysis that addresses two key questions dealing with dependence and cessation: (1) are menthol smokers more likely to smoke their first cigarette of the day sooner than non-menthol smokers (TTFC), and (2) is there an association between menthol smoking and cessation rates?

\section{METHODS}

\section{Identification of relevant studies}

For TTFC the initial basis for the literature selection was all references cited in a recent FDA report (3). A literature search was also conducted in PubMed and the Cochrane database using the terms "time to first cigarette [and] menthol", "dependence [and] menthol", and "time to first cigarette". References were checked from all retained papers, and a search was performed in PubMed for "similar articles" to check for completeness.

Similarly, for cessation studies, articles were identified from the FDA report and from the results of a PubMed and Cochrane database search using the terms "smoking cessation [and] menthol". References were checked from all retained papers and from two review articles $(4,5)$, and a search was performed in PubMed for "similar articles" to check for any missed studies.

All papers published until February 2015 were included, provided that the data were available in a format that allowed calculation of an odds ratio (OR) and confidence interval (CI) for use in the meta-analysis. This was the only inclusion criterion. 


\section{Selection of estimates}

Where multiple papers were based on the same source data for either TTFC or cessation, the paper that utilized the largest percentage of the data was generally selected. In some cases additional criteria were required to determine which paper should be selected (see Appendices A and C). This process was conducted prior to inspection of the results or to any calculations being made.

Where papers presented multiple estimates, the following criteria were applied to select the estimates for inclusion in the meta-analyses.

1. Preference was given to adjusted estimates as opposed to unadjusted estimates, with a specific exception noted in the next point.

2. Cessation estimates for which an adjustment had been made for TTFC or a dependence index that includes TTFC, such as the Heaviness of Smoking Index (HSI) (6) or the Fagerström Test for Nicotine Dependence (FTND) (7), were not included in any of the metaanalyses. These estimates were excluded to avoid overadjustment $(8,9)$.

3. For RCT studies, all estimates are based on intention-totreat effects, and the estimate relating to the longest period of cessation up to and including one year was selected. This selection rule was maintained even if it was necessary to utilize an unadjusted OR as opposed to an adjusted $\mathrm{OR}$.

\section{Statistics}

The DerSimonian-Laird method was used to meta-analyze the data and was implemented in an Excel spreadsheet based on the description provided by NORMAND (10). This methodology uses weighting by inverse standard error and provides both fixed-effect and random-effects pooled results. Given that ORs are lognormally distributed, the meta-analyses were conducted on the natural log of the ORs $(\ln (\mathrm{OR}))$. Standard errors of $\ln (\mathrm{OR})$ were calculated when not provided in the relevant publication either directly from the $95 \%$ CI or by calculating the variance of the $\ln (\mathrm{OR})$ from the raw data. Reference categories for ORs were non-mentholated cigarettes in the TTFC analysis and menthol cigarettes in the cessation analysis. This was done in order to be consistent with the vast majority of the published literature.

Sensitivity analysis was conducted according to VANDERWEELE and ARAH (11) based on adjusting estimates and confidence interval limits according to a bias factor. This factor is calculated on the basis of specified exposure prevalence levels of an unmeasured binary confounder $U$ (see the Results section for a detailed discussion of $U$ ) in the two exposure groups as well as on an assumed effect size of the unmeasured confounder on the outcome. A general assumption of the method is that the effect of $U$ on the outcome is constant across the considered exposure levels/groups.

Pairwise comparison of ORs to assess if differences were statistically significant was conducted using the $\mathrm{z}$ test at a $5 \%$ level of significance as for all other inferential comparisons. Funnel plots were created using the metafor package in $\mathrm{R}$.

\section{RESULTS}

\section{Time to first cigarette (TTFC)}

Of the 57 publications identified as potentially relevant in the literature search conducted for menthol smokers and TTFC, 18 were identified with results meeting the inclusion criterion. These papers are listed in Appendix B, which provides demographic data as well as information on each study. All studies were cross-sectional and all were conducted in the US except for HYLAND et al. (12) for which about $10 \%$ of the subjects were Canadian. The 30 nonoverlapping estimates taken from 15 out of these 18 publications that were used for the meta-analyses are listed in Table 1. Explanation of the choice of estimates to be

Table 1. Results (US) for time to first cigarette (TTFC).

\begin{tabular}{|c|c|c|c|c|c|c|c|c|c|c|}
\hline \multirow{2}{*}{$\begin{array}{l}\text { Est. } \\
\text { No. }\end{array}$} & \multirow{2}{*}{$\begin{array}{l}\text { Publ. } \\
\text { No. }\end{array}$} & \multirow{2}{*}{ First author } & \multirow{2}{*}{ Year } & \multirow{2}{*}{$\begin{array}{l}\text { Sample } \\
\text { size }\end{array}$} & \multirow{2}{*}{$\begin{array}{c}\text { Menth. } \\
\text { smokers } \\
(\%)\end{array}$} & \multirow{2}{*}{$\begin{array}{c}\text { TTFC } \\
\text { range } \\
\text { (min) }\end{array}$} & \multicolumn{2}{|c|}{$\begin{array}{l}\text { Number of smokers } \\
\text { in TTFC range }(\%)\end{array}$} & \multirow{2}{*}{$\begin{array}{c}\text { Covariates } \\
\text { adjusted for [a] }\end{array}$} & \multirow{2}{*}{$\mathrm{OR}, 95 \% \mathrm{Cl}[\mathrm{b}]$} \\
\hline & & & & & & & Menthol & Non-menthol & & \\
\hline 1 & 1 & HYLAND (12) & 2002 & $13,268[c]$ & 24.0 & $<10$ & $947(29.7 \%)$ & $3,338(33.1 \%)$ & $\begin{array}{l}\mathrm{s}, \mathrm{a}, \mathrm{r}, \mathrm{edu}, \mathrm{cpd} \\
\text { other [d] }\end{array}$ & $0.90,0.81-0.99$ \\
\hline 2 & 1 & HYLAND (12) & 2002 & $13,268[\mathrm{c}]$ & 24.0 & $\leq 30$ & $1,699(56.0 \%)$ & $6,520(63.9 \%)$ & None & $0.72,0.66-0.78[\mathrm{e}]$ \\
\hline 3 & 2 & OKUYEMI (31) & 2003 & 600 & 78.5 & $\leq 30$ & $385(81.7 \%)$ & $90(69.8 \%)$ & None & $1.94,1.25-3.02[\mathrm{e}]$ \\
\hline 4 & 3 & COLLINS (32) & 2006 & 572 & 92.8 & $\leq 5$ & $239(45 \%)$ & $12(29 \%)$ & None & $1.98,0.99-3.96[\mathrm{e}]$ \\
\hline 5 & 3 & COLLINS (32) & 2006 & 572 & 92.8 & $\leq 30$ & $398(75 \%)$ & $27(66 \%)$ & None & $1.55,0.79-3.05[\mathrm{e}]$ \\
\hline 6 & 4 & Fu (33) & 2008 & 1,343 & 25.5 & $\leq 30$ & $256(75 \%)$ & $791(79 \%)$ & None & $0.79,0.59-1.05[\mathrm{e}]$ \\
\hline 7 & 5 & GANDHI (34) & 2009 & 1,664 & 46.1 & $\leq 5$ & $187(24.3 \%)$ & $178(19.9 \%)$ & None & $1.30,1.03-1.64[\mathrm{e}]$ \\
\hline 8 & 5 & GANDHI (34) & 2009 & 1,664 & 46.1 & $\leq 30$ & $622(81.0 \%)$ & $744(83.0 \%)$ & None & $0.87,0.68-1.12[\mathrm{e}]$ \\
\hline 9 & 6 & MUSCAT (35) & 2009 & 525 & 54.1 & $\leq 30$ & n.a. $(34 \%)$ & n.a. $(21 \%)$ & $\mathrm{s}, \mathrm{a}, \mathrm{r}, \mathrm{edu}$ & $2.1,0.96-3.8$ \\
\hline 10 & 7 & $\begin{array}{l}\text { FAGAN, } \\
\leq 5 \text { cpd }(36)\end{array}$ & 2010 & 3,541 & 33.0 & $\leq 5$ & & & $\begin{array}{c}\text { a, r, edu, inc, } \\
\text { occ, aoo, dur, } \\
\text { ss-12 }\end{array}$ & $0.94,0.60-1.47$ \\
\hline 11 & 7 & $\begin{array}{l}\text { FAGAN, } \\
6-10 \mathrm{cpd}(36)\end{array}$ & 2010 & 11,873 & 31.1 & $\leq 5$ & & & $\begin{array}{l}\text { s, a, r, edu, mar, } \\
\text { inc, occ, reg, } \\
\text { met, aoo, dur, } \\
\text { ss-12 }\end{array}$ & $1.22,1.05-1.43$ \\
\hline
\end{tabular}




\begin{tabular}{|c|c|c|c|c|c|c|c|c|c|c|}
\hline \multirow{2}{*}{$\begin{array}{l}\text { Est. } \\
\text { No. }\end{array}$} & \multirow{2}{*}{$\begin{array}{l}\text { Publ. } \\
\text { No. }\end{array}$} & \multirow{2}{*}{ First author } & \multirow{2}{*}{ Year } & \multirow{2}{*}{$\begin{array}{c}\text { Sample } \\
\text { size }\end{array}$} & \multirow{2}{*}{$\begin{array}{c}\text { Menth. } \\
\text { smokers } \\
(\%)\end{array}$} & \multirow{2}{*}{$\begin{array}{l}\text { TTFC } \\
\text { range } \\
\text { (min) }\end{array}$} & \multicolumn{2}{|c|}{$\begin{array}{l}\text { Number of smokers } \\
\text { in TTFC range (\%) }\end{array}$} & \multirow{2}{*}{$\mid \begin{array}{c}\text { Covariates } \\
\text { adjusted for } \\
\text { [a] }\end{array}$} & \multirow{2}{*}{ OR, 95\% Cl [b] } \\
\hline & & & & & & & Menthol & Non-menthol & & \\
\hline 12 & 7 & $\begin{array}{l}\text { FAGAN, } \\
11-19 \mathrm{cpd}(36)\end{array}$ & 2010 & 6,405 & 25.7 & $\leq 5$ & & & $\begin{array}{c}\text { s, a, r, edu, } \\
\text { mar, inc, } \\
\text { occ, reg, } \\
\text { met, aoo, } \\
\text { dur, ss-12, } \\
\text { itq(10) }\end{array}$ & $1.18,0.97-1.45$ \\
\hline 13 & 7 & $\begin{array}{l}\text { FAGAN, } \\
>20 \mathrm{cpd}(36)\end{array}$ & 2010 & 23,496 & 22.0 & $\leq 5$ & & & $\begin{array}{c}\text { s, a, r, edu, } \\
\text { mar, inc, } \\
\text { occ, reg, } \\
\text { met, aoo, } \\
\text { dur, ss-12, } \\
\text { itq(30) }\end{array}$ & $1.03,0.95-1.13$ \\
\hline 14 & 7 & $\begin{array}{l}\text { FAGAN, } \\
\leq 5 \mathrm{cpd}(36)\end{array}$ & 2010 & 3,541 & 33.0 & $\leq 30$ & & & $\begin{array}{c}\text { a, r, edu, inc, } \\
\text { occ, aoo, } \\
\text { dur, ss-12 }\end{array}$ & $1.20,0.96-1.50$ \\
\hline 15 & 7 & $\begin{array}{l}\text { FAGAN, } \\
6-10 \mathrm{cpd}(36)\end{array}$ & 2010 & 11,873 & 31.1 & $\leq 30$ & & & $\begin{array}{c}\text { s, a, r, edu, } \\
\text { mar, inc, } \\
\text { occ, reg, } \\
\text { met, aoo, } \\
\text { dur, ss-12, yr }\end{array}$ & $1.09,0.97-1.22$ \\
\hline 16 & 7 & $\begin{array}{l}\text { FAGAN, } \\
11-19 \mathrm{cpd} \\
(36)\end{array}$ & 2010 & 6,405 & 25.7 & $\leq 30$ & & & $\begin{array}{c}\text { s, a, r, edu, } \\
\text { mar, inc, } \\
\text { occ, reg, } \\
\text { met, aoo, } \\
\text { dur, ss-12, } \\
\text { itq(30) }\end{array}$ & $0.98,0.84-1.14$ \\
\hline 17 & 7 & $\begin{array}{l}\text { FAGAN, } \\
>20 \mathrm{cpd}(36)\end{array}$ & 2010 & 23,496 & 22.0 & $\leq 30$ & & & $\begin{array}{c}\text { a, r, edu, } \\
\text { mar, inc, } \\
\text { occ, reg, } \\
\text { met, yr, aoo, } \\
\text { dur, ss-12, } \\
\text { itq(30) }\end{array}$ & $1.05,0.95-1.16$ \\
\hline 18 & 8 & $\begin{array}{l}\text { AHIJEVYCH (37), } \\
\text { daily smokers }\end{array}$ & 2010 & 2,241 & 29.9 & $\leq 30$ & & & $\begin{array}{l}\mathrm{s}, \mathrm{r}, \mathrm{edu} \\
\mathrm{occ}, \mathrm{hsr}[\mathrm{f}]\end{array}$ & $1.16,0.98-1.38[\mathrm{~g}]$ \\
\hline 19 & 8 & $\begin{array}{l}\text { AHIJEVYCH (37), } \\
\text { non-daily smokers }\end{array}$ & 2010 & 688 & 25.7 & $\leq 30$ & & & $\mathrm{~s}, \mathrm{r}, \mathrm{scal}[\mathrm{f}]$ & $2.03,1.09-3.78[\mathrm{~g}]$ \\
\hline 20 & 10 & FASERU (38) & 2011 & 540 & 83.7 & $\leq 30$ & $330(73.0 \%)$ & 60 (68.2\%) & None & $1.26,0.77-2.07[\mathrm{e}]$ \\
\hline 21 & 11 & REITZEL (39) & 2011 & 244 & 50.5 & $\leq 5$ & $90(73.2 \%)$ & $101(83.5 \%)$ & None & $0.54,0.29-1.01[\mathrm{e}]$ \\
\hline 22 & 12 & D'SILVA (40) & 2012 & 6,257 & 18.7 & $\leq 5$ & $543(46.3 \%)$ & $2,192(43.1 \%)$ & None & $1.14,1.00-1.29[\mathrm{e}]$ \\
\hline 23 & 13 & ROSENBLOOM (41) & 2012 & 928 & 36.1 & $\leq 5$ & $164(49.0 \%)$ & $213(36.0 \%)$ & None & $1.71,1.30-2.25[\mathrm{e}]$ \\
\hline 24 & 16 & ROJEWSKI (42) & 2014 & 166 & 36.7 & $\leq 30$ & $47(82.4 \%)$ & $83(79.8 \%)$ & None & $1.19,0.52-2.74[\mathrm{e}]$ \\
\hline 25 & 17 & FROST-PINEDA (43) & 2014 & 3,341 & 31.2 & $\leq 5$ & $337(33.8 \%)$ & $661(30.1 \%)$ & None & $1.19,1.01-1.39[\mathrm{e}]$ \\
\hline 26 & 17 & FROST-PINEDA (43) & 2014 & 3,341 & 31.2 & $\leq 30$ & $782(74.9 \%)$ & $1,636(71.2 \%)$ & $\begin{array}{c}\text { s, a, r, edu, } \\
\text { "tar" }\end{array}$ & $1.17,0.96-1.42$ \\
\hline 27 & 18 & CURTIN (44) [h] & 2014 & 77,183 & 32.0 & $\leq 5$ & $5,383(21.8 \%)$ & $10,457(19.9 \%)$ & None & $1.12,1.08-1.16[e]$ \\
\hline 28 & 18 & CURTIN (44) [h] & 2014 & 77,183 & 32.0 & $\leq 30$ & $13,231(53.5 \%)$ & $27,643(52.7 \%)$ & None & $1.03,1.00-1.06[\mathrm{e}]$ \\
\hline 29 & 18 & CURTIN (44) [i] & 2014 & 4,759 & 31.6 & $\leq 5$ & $492(32.7 \%)$ & $1,007(30.9 \%)$ & None & $1.08,0.95-1.24[\mathrm{e}]$ \\
\hline 30 & 18 & CURTIN (44) [i] & 2014 & 4,759 & 31.6 & $\leq 30$ & $910(60.5 \%)$ & $1,970(60.5 \%)$ & None & $1.00,0.88-1.13[\mathrm{e}]$ \\
\hline
\end{tabular}

[a] Abbreviations: a - age; aoo - age of onset; cpd - cigarettes/day; dur - daily smoking duration; edu - education; hsr = home smoking rules; inc - annual family income; itq() - intention to quit (days); mar - marital status; met - metropolitan status; occ employment/occupational status; $r$ - race; reg - region; s - sex; scal - state clean air laws; ss-12 - smoking status 12 months ago; "tar" - "tar" yield; yr - survey year.

[b] OR >1 indicates a greater likelihood of menthol smokers smoking their first cigarette earlier than non-menthol smokers.

[c] Includes 1,382 Canadian smokers.

[d] Other covariates: history of past serious quit attempts, age started smoking, desire to stop smoking, frequency of alcohol consumption, use of a non-cigarette tobacco product, pricing tier of cigarette smoked, presence of another smoker in household.

[e] Calculated from data provided using $2 \times 2$ table.

[f] Covariates that were significant in the multivariate model.

[g] OR and $95 \% \mathrm{Cl}$ calculated from the binary logit model coefficient and standard error.

[h] Data were obtained from the 2001-2009 National Survey on Drug Use and Health (NSDUH).

[i] Data were obtained from NHANES, 2001-2010. 
included is provided in Appendix A, which also includes an analysis demonstrating that the choices made do not bias the results in the direction of a longer TTFC for menthol smokers.

Overall, 5 meta-analyses were performed on the appropriate data from the selected 30 TTFC estimates. These included an overall meta-analysis utilizing the shortest time period for each study ( $\mathrm{N}=20$ estimates), two subgroup analyses for studies that reported data on TTFC $\leq 5$ minutes $(\mathrm{N}=13)$ or TTFC $\leq 30$ minutes $(\mathrm{N}=17)$; and finally for large studies $(>1,000$ subjects, $\mathrm{N}=12)$ or small studies $(<1,000$ subjects, $\mathrm{N}=8$ ), again using the shortest time period available. The results of these meta-analyses are reported in Table 2.

For the overall meta-analysis both fixed-effect and randomeffects models indicate a small but significant difference between menthol and non-menthol cigarette smokers, with menthol cigarette smokers being more likely to smoke their first cigarette in the morning before non-menthol cigarette smokers. When comparing studies that determined TTFC of $\leq 5 \mathrm{~min}$ alone, the estimates also indicate that menthol cigarette smokers were more likely to smoke their first cigarette within 5 minutes of waking as compared to nonmenthol cigarette smokers. For the studies that report TTFC of $\leq 30 \mathrm{~min}$, although menthol cigarette smokers were more likely to smoke their first cigarettes within $30 \mathrm{~min}$ of waking, neither the fixed-effect nor the random-effects pooled estimate was statistically significant. The difference between the two fixed-effect estimates $(\leq 5 \mathrm{~min}$ or $\leq 30$ min) was statistically significant $(p<0.0001)$, however there was no statistically significant difference between the 2 random-effects estimates $(p=0.37)$. It can be observed from Table 2 that there was a considerable amount of heterogeneity in the result obtained when the 20 estimates representing the shortest time period from each study were combined $\left(\mathrm{I}^{2}=69 \%\right)$. Stratification of the results based on time period ( $\leq 5$ or $\leq 30 \mathrm{~min}$ ) led to an increase in heterogeneity for both sets of pooled results, indicating that this factor does not contribute to the heterogeneity of the pooled result for all studies.

The second comparison that was made concerns study size. Some of the studies were very large population-based studies, whereas others were small, usually based on baseline data from subjects who participated in clinical studies. Setting $N=1,000$ subjects as the arbitrary dividing point resulted in two groups of estimates, with 8 estimates for small studies $(\mathrm{N}=166-928)$ and 12 estimates for large studies $(\mathrm{N}=1,343-77,183)$. The results show that the tendency for menthol cigarette smokers to be more likely than non-menthol cigarette smokers to smoke their first cigarette of the morning early is much more clearly seen in small than in large studies, a difference that is statistically significant. Once again, considerable heterogeneity remained for these pooled estimates. It should be noted that no stratification by race could be performed, since none of the studies provided usable TTFC data stratified for both menthol and race.

In order to check for publication bias, we created a funnel plot for those studies that were used to calculate the pooled meta-analytic result for TTFC $\leq 5$ min (Figure E1, Appendix E). As can be seen, there are quite a few studies missing to the left of the point estimate of 1.12, the pooled random-effects meta-analytic result for these estimates. This indicates that the estimate being $>1$ is at least partially due to publication bias; that is, there appears to be a preference to publish studies with OR $>1$. Therefore, the differences between menthol and non-menthol with respect to $\mathrm{TTFC} \leq 5 \mathrm{~min}$, which is already quite modest, may well be to some extent a result of publication bias.

To summarize, the estimates for TTFC indicate that menthol cigarette smokers have a tendency to smoke their first cigarette in the morning earlier than do non-menthol smokers. The increase in the ORs for TTFC associated with menthol smokers is modest, with small studies showing a $40-50 \%$ increase, while all other categories indicated only about a $10 \%$ increase, except for TTFC of 30 min which showed no increase. In addition, as shown by an analysis of publication bias, this small difference may be even further reduced. It has been suggested that a decrease in TTFC associated with menthol smokers would indicate a concomitant increase in difficulty in smoking cessation for menthol smokers. In order to investigate this possibility, a second set of meta-analyses on studies comparing cessation rates between menthol and non-menthol smokers has been performed and is described below.

\section{Smoking cessation - description of studies}

Of the 69 publications identified as potentially relevant in the literature search conducted for menthol cigarette smokers and smoking cessation, 27 were identified that reported results meeting the inclusion criteria; 2 of those presented data on two different studies. These papers are listed in Appendix D, which provides demographic data as well as information on the studies. All studies were conducted in the US except as previously noted for HYLAND et al. (12). Of the 29 studies listed in Appendix D, 13 were randomized controlled trials (RCT), 10 were cross-

Table 2. Meta-analytic results for TTFC.

\begin{tabular}{l|c|c|c}
\hline Description of group (N) & Fixed-effect OR $(95 \% \mathrm{Cl})^{\mathrm{a}}$ & ${\text { Random-effects OR }(95 \% \mathrm{Cl})^{\mathrm{a}}}$ & $\mathrm{I}^{2 \mathrm{~b}}$ \\
\hline Shortest time period (20) & $1.10(1.07-1.13)$ & $1.14(1.06-1.23)$ & 69.17 \\
TTFC $\leq 5$ min (13) & $1.10(1.07-1.13)$ & $1.12(1.04-1.21)$ & 71.76 \\
TTFC $\leq 30$ min (17) & $1.01(0.99-1.04)$ & $1.06(0.96-1.16)$ & 84.20 \\
Small studies $(<1000)(8)$ & $1.57(1.32-1.86)$ & $1.51(1.13-2.00)$ & 54.73 \\
Large studies $(>1000)(12)$ & $1.08(1.05-1.11)$ & $1.08(1.00-1.16)$ & 76.13
\end{tabular}

\footnotetext{
${ }^{a}$ OR $>1$ indicates a greater likelihood of menthol smokers smoking their first cigarette earlier than non-menthol smokers

b Index of heterogeneity-attributable variance percent
} 
sectional, 5 were prospective studies, and 1 was a retrospective cohort study. There were 3 studies that analyzed data from the National Health Interview Survey Cancer Control Supplement (NHIS-CCS), and 4 studies that analyzed data from the Tobacco Use Supplement to the US Current Population Survey (TUS-CPS). To avoid overlap, only one study from each group was chosen for inclusion in the meta-analysis. The rationale for the choice of study used is provided in Appendix C.

Table 3 contains the 43 estimates derived from nonoverlapping studies used for the meta-analysis of cessation rates for menthol and non-menthol smokers. These estimates have been selected using the criteria specified in the Methods section. Estimates 42 and 43 derived from SULSKY et al. (2014) (publication \#27) (13) require a special comment. The published $95 \%$ confidence limits appeared to be too narrow, leading to a very large weight for these estimates. Given that the actual number of subjects was not specified, this point could not be checked. Discussions between Mr. Peter N. Lee, of PN Lee Statistics \& Computing, and Dr. Sulsky led to an acknowledgment that the confidence limits were indeed too narrow and revised estimates that will be published as a correction (P.N. Lee, personal communication). The estimates shown in Table 3 are these corrected estimates.

\section{Smoking cessation - meta-analyses}

The results of various meta-analyses on the cessation data are shown in Table 4 . The first result considers all subjects, with no stratification based on race $(\mathrm{N}=30)$. Both the fixed-effect and the random-effects results indicate a very small but statistically significant difference with respect to cessation rates between menthol and non-menthol smokers, suggesting that menthol smokers find it more difficult to quit. Stratification of these studies by race provides an interesting contrast. The pooled fixed-effect and random-effects results for the 10 estimates for Caucasian smokers indicate that there is no difference in cessation rates between menthol and nonmenthol smokers. The situation for African American subjects (14 estimates) is rather different. Both the fixed-effect and the random-effects pooled $\mathrm{ORs}(\mathrm{OR}=0.93,95 \% \mathrm{CI}$, $0.87-0.98$ and $\mathrm{OR}=0.76,95 \% \mathrm{CI}, 0.62-0.92$, respectively) show a statistically significant difference indicating that African American menthol cigarette smokers find it more difficult to quit smoking than African American non-menthol cigarette smokers, although the difference for the fixed-effect estimate is small. The pooled results for the small number of estimates (4) for Hispanic smokers do not show a statistically significant difference for cessation rates between menthol and non-menthol cigarette smokers.

Lastly, as with TTFC, we compared large studies to small studies. In this case, rather than simply using size as the differentiating factor, longitudinal and cross-sectional (population) studies, which are invariably large $(\mathrm{N}=1,343-65,316)$, were compared to RCTs, which tend to be small $(\mathrm{N}=109-1439)$. As can be seen there is no difference between cessation rates in menthol cigarette smokers and non-menthol cigarette smokers in the large studies $(\mathrm{N}=13)$. For the 17 RCT estimates, however, there was a clear difference between menthol and non-menthol cigarette smokers. The pooled fixed-effect OR was 0.73
(95\% CI, 0.65-0.81) and the pooled random-effects OR was 0.70 (95\% CI, 0.60-0.82). Both of these results show a statistically significant disadvantage with respect to cessation rates in menthol cigarette smokers. Simple inspection indicates that the differences between the pooled ORs for population and RCT estimates are statistically significant. As was the case for the TTFC results, there was considerable heterogeneity when results were obtained for population and RCT studies grouped together, and the level of heterogeneity remained high when the results were stratified by race. Stratification by study size resulted in a considerable reduction of heterogeneity for $\mathrm{RCT}$ estimates $\left(\mathrm{I}^{2}=42 \%\right)$ but not for population estimates $\left(\mathrm{I}^{2}=91 \%\right)$. However, there was close agreement between the fixed-effect and random-effects pooled estimates for both types of studies.

To summarize, these results are somewhat inconsistent. They indicate that African American menthol cigarette smokers have more difficulty quitting than African American non-menthol cigarette smokers. Secondly, the results from RCT studies also clearly support a greater difficulty for menthol smokers to quit compared to nonmenthol smokers. On the other hand, the reverse was true for Caucasians, where Caucasian menthol cigarette smokers appear to be directionally slightly more likely to successfully quit smoking than are Caucasian non-menthol cigarette smokers. Lastly, there was no difference in cessation results for population studies comparing menthol to non-menthol cigarette smokers.

We also investigated possible publication bias for cessation results, and the relevant funnel plot is shown in Figure E2, Appendix E. In this case it can be seen that there are quite a few studies missing to the right of 0.87 , the pooled random-effects meta-analytic results for all included cessation studies not stratified by race. This indicates that the fact that the estimate is $<1$ is perhaps partially due to publication bias; that is, there appears to be a preference to publish studies with OR $<1$.

\section{Effect of residual confounding - description of approach}

A possible explanation for the difference in comparative cessation rates for African American menthol cigarette smokers compared to Caucasian menthol cigarette smokers might be residual confounding. To attempt to quantitatively determine if such a residual confounder could significantly affect the results, we conducted a conceptual sensitivity analysis. This was done by assuming that some unmeasured confounder, designated as $\mathrm{U}$, might be related both to the exposure, i.e., type of cigarette smoked (menthol vs. nonmenthol), as well as to the outcome under consideration, i.e., TTFC or cessation. This sensitivity analysis indicated that if such a confounder $U$ would be two to three times as prevalent in menthol than in non-menthol cigarette smokers (70 vs. 25 percent), an association of $U$ and TTFC of the same magnitude as the random-effects OR estimate of cigarette type on TTFC of 1.14 (95\% CI,1.06-1.23) would reduce that estimate to $1.07(95 \% \mathrm{CI}, 1.00-1.16)$ upon adjustment for $\mathrm{U}$. The overall random-effects estimate of cigarette type on cessation would be upwardly adjusted by $\mathrm{U}$ from 0.87 (95\% CI, $0.80-0.96)$ to 0.91 (95\% CI, 0.83-1.00), by assuming a prevalence of $U$ in menthol smokers of 55 percent (rather than 70 percent as in the above TTFC case) 


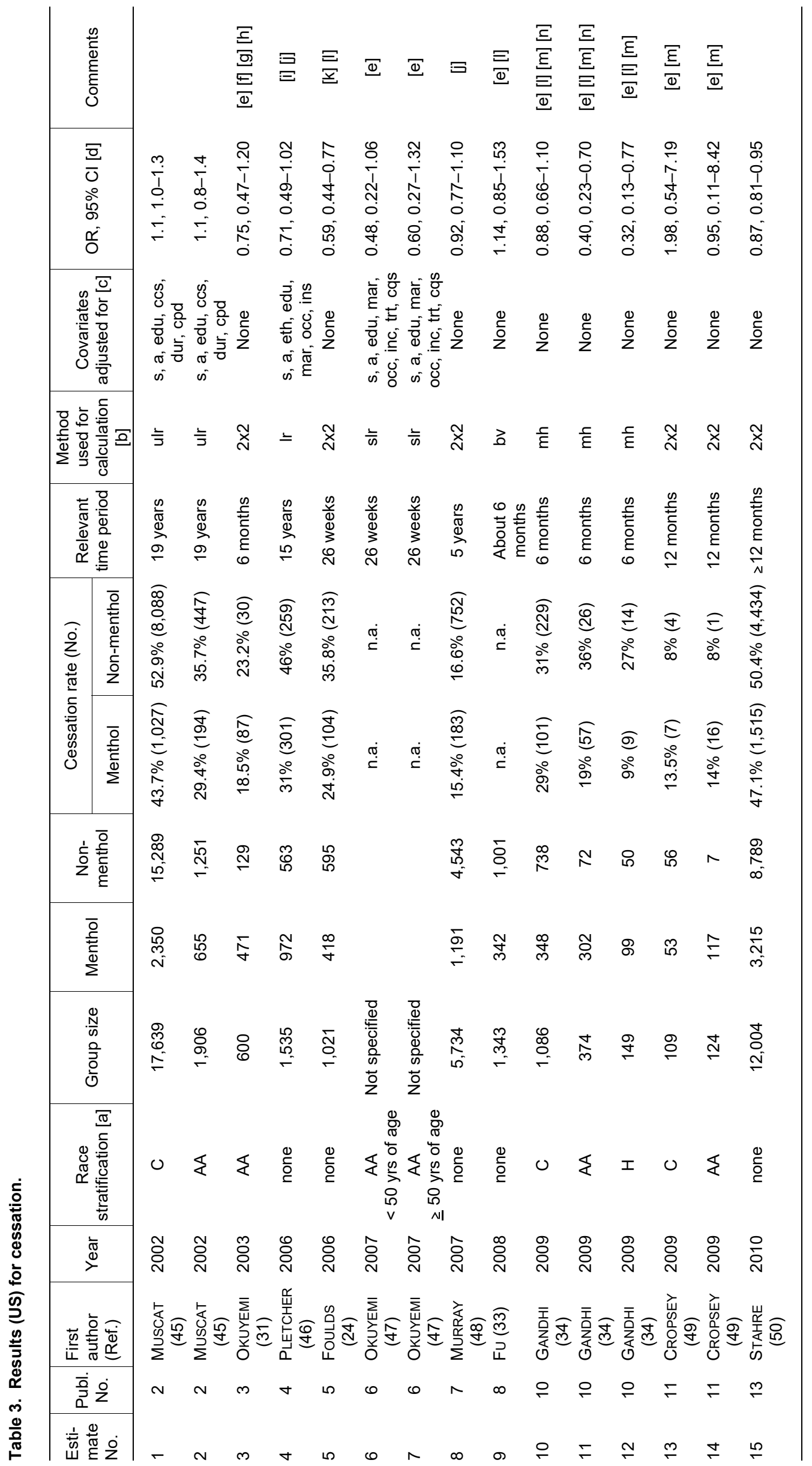




\begin{tabular}{|c|c|c|c|c|c|c|c|c|c|c|c|c|c|c|}
\hline 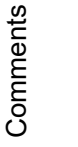 & $\bar{\Xi}$ & $\bar{a}$ & & $\begin{array}{l}\overline{\widetilde{\sigma}} \\
\underline{\widetilde{\sigma}}\end{array}$ & $\begin{array}{l}\Xi \\
\Xi\end{array}$ & $\begin{array}{l}\overline{\underline{\omega}} \\
\underline{\underline{E}} \\
\bar{\sigma}\end{array}$ & 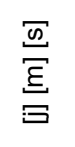 & $\frac{\underline{\Phi}}{\underline{\Xi}}$ & $\begin{array}{l}\underline{\Xi} \\
\underline{E}\end{array}$ & $\underline{\xi}$ & $\underline{E}$ & $\underline{E}$ & & \\
\hline 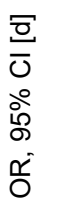 & 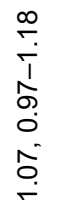 & $\begin{array}{l}8 \\
0 \\
0 \\
1 \\
9 \\
0 \\
0 \\
10 \\
0 \\
0 \\
0\end{array}$ & 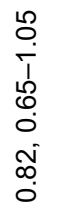 & 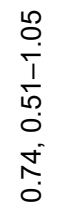 & 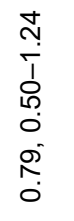 & 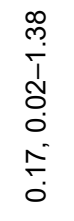 & \begin{tabular}{l} 
m \\
\multirow{5}{*}{} \\
\\
0 \\
0 \\
0 \\
0 \\
0 \\
0 \\
0
\end{tabular} & 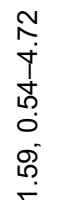 & 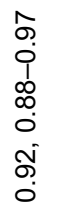 & 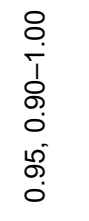 & $\begin{array}{l}\mathscr{L} \\
0 \\
0 \\
1 \\
0 \\
0 \\
0 \\
\infty \\
\infty \\
0\end{array}$ & 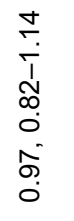 & $\begin{array}{l}\stackrel{R}{+} \\
\frac{1}{+} \\
\stackrel{+}{+} \\
\stackrel{0}{0} \\
\stackrel{0}{+}\end{array}$ & 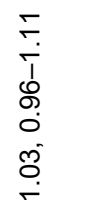 \\
\hline 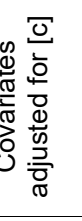 & $\begin{array}{l}0 \\
\stackrel{0}{0} \\
\text { z }\end{array}$ & $\begin{array}{l}0 \\
\stackrel{0}{0}\end{array}$ & $\frac{0}{2}$ & $\stackrel{0}{\tilde{0}}$ & $\stackrel{0}{\frac{0}{0}}$ & $\begin{array}{l}0 \\
\stackrel{0}{0}\end{array}$ & $\stackrel{0}{\tilde{0}}$ & $\stackrel{0}{\stackrel{0}{0}}$ & 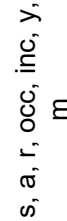 & 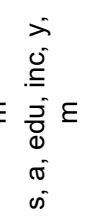 & 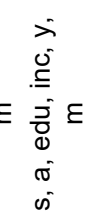 & 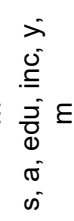 & 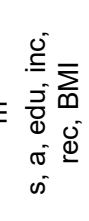 & 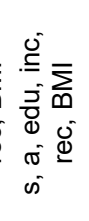 \\
\hline 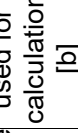 & $\underset{\text { X }}{x}$ & x & $\underset{x}{x}$ & $\underset{\mathrm{X}}{x}$ & $\overline{0}$ & $\underset{x}{x}$ & $\underset{\mathrm{N}}{x}$ & x & $\stackrel{\iota}{\bar{\varepsilon}}$ & $\overline{\bar{\varepsilon}}$ & $\frac{}{\varepsilon}$ & $\stackrel{\grave{\xi}}{\xi}$ & 늑 & $\frac{\grave{ }}{3}$ \\
\hline 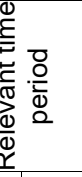 & 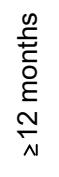 & 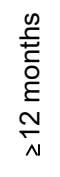 & 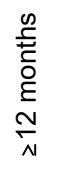 & 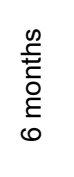 & 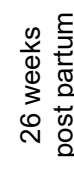 & 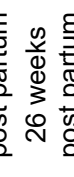 & 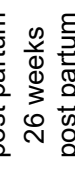 & 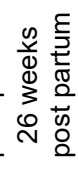 & $\sum_{\infty}^{\infty}$ & $\overbrace{\omega}^{\frac{\infty}{\pi}}$ & 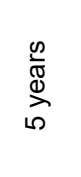 & 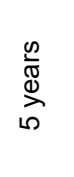 & 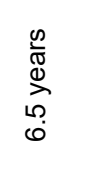 & 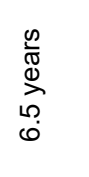 \\
\hline 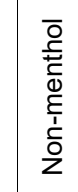 & 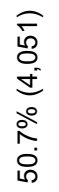 & 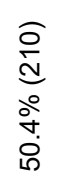 & 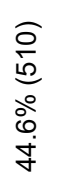 & 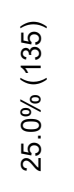 & $\stackrel{\text { }}{\check{\Phi}}$ & $\begin{array}{l}\stackrel{\widehat{O}}{0} \\
\stackrel{\circ}{\stackrel{\circ}{N}}\end{array}$ & $\begin{array}{l}\widehat{Ð} \\
\stackrel{0}{\circ} \\
\text { i }\end{array}$ & $\begin{array}{l}\widehat{\alpha} \\
\stackrel{0}{\circ} \\
\stackrel{\infty}{\leftarrow}\end{array}$ & 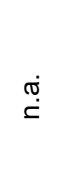 & Фேं & 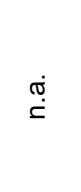 & 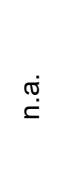 & 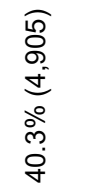 & 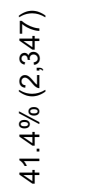 \\
\hline $\begin{array}{l}\overline{0} \\
+\frac{c}{ \pm} \\
\overline{0} \\
\sum\end{array}$ & 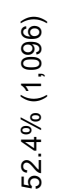 & $\begin{array}{l}\widehat{\widetilde{0}} \\
\stackrel{0}{0} \\
\stackrel{0}{\circ} \\
\dot{0} \\
\dot{m}\end{array}$ & 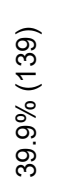 & $\begin{array}{l}\widehat{\widehat{D}} \\
\stackrel{0}{0} \\
\stackrel{\circ}{0} \\
\stackrel{\circ}{\circ}\end{array}$ & 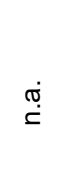 & 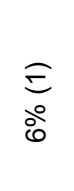 & 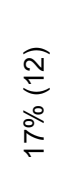 & $\begin{array}{l}\widehat{D} \\
\stackrel{0}{A} \\
\stackrel{N}{N}\end{array}$ & 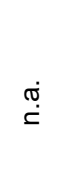 & $\stackrel{\text { đேं }}{\check{c}}$ & $\stackrel{\text { ֻே் }}{\check{c}}$ & 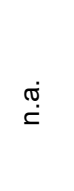 & 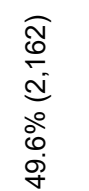 & 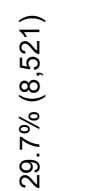 \\
\hline 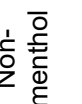 & $\begin{array}{l}\stackrel{0}{\infty} \\
\stackrel{\circ}{N}\end{array}$ & 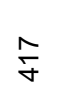 & $\stackrel{\text { fo }}{\check{r}}$ & 움 & 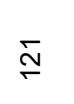 & 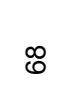 & $F$ & テ & $\begin{array}{l}\frac{m}{6} \\
\dot{\sigma}\end{array}$ & 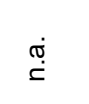 & $\stackrel{\text { ஸ் }}{\check{c}}$ & $\stackrel{\text { ஸ் }}{\check{S}}$ & $\begin{array}{l}\underset{\Xi}{\sigma} \\
\stackrel{\sim}{\Im}\end{array}$ & $\begin{array}{l}8 \\
\& \\
10\end{array}$ \\
\hline 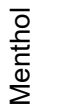 & $\begin{array}{l}\text { Oे } \\
\text { i }\end{array}$ & $\stackrel{N}{\circ}$ & $\stackrel{\infty}{m^{*}}$ & $\stackrel{8}{\mathrm{~N}}$ & $\stackrel{\Re}{\sim}$ & ㅇ & $R$ & $\ddot{m}$ & $\begin{array}{l}\stackrel{\Re}{R} \\
\stackrel{2}{\leftarrow}\end{array}$ & 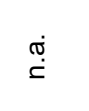 & 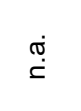 & $\stackrel{\oplus}{\check{\Gamma}}$ & $\begin{array}{l}\infty \\
\stackrel{\infty}{\infty} \\
\stackrel{\sim}{0}\end{array}$ & \begin{tabular}{l}
0 \\
0 \\
0 \\
\multirow{N}{0}{}
\end{tabular} \\
\hline $\begin{array}{l}\stackrel{0}{N} \\
\frac{N}{\omega} \\
\frac{0}{0} \\
\frac{0}{0}\end{array}$ & 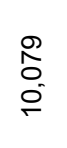 & 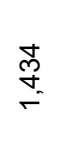 & 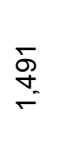 & \&̊․․ & $\stackrel{\mathbb{N}}{N}$ & $\infty$ & $\bar{\infty}$ & $\stackrel{\mathfrak{R}}{\sim}$ & $\begin{array}{l}0 \\
0 \\
0 \\
0 \\
0\end{array}$ & 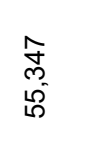 & $\underset{\substack{f \\
\leftarrow \infty}}{\infty}$ & 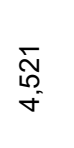 & $\begin{array}{l}\mathbb{N} \\
\mathbb{N} \\
\stackrel{0}{0}\end{array}$ & $\begin{array}{l}\text { Fै } \\
\text { J } \\
\text { fే }\end{array}$ \\
\hline 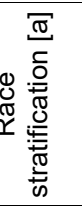 & 0 & $\varangle$ & $I$ & $\stackrel{\oplus}{\check{0}}$ & $\stackrel{\oplus}{\text { ¿ }}$ & 0 & $\varangle$ & $I$ & $\stackrel{\varpi}{\text { こ }}$ & 0 & $\varangle$ & $I$ & 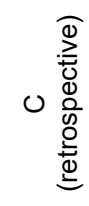 & 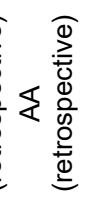 \\
\hline 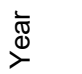 & 울 & 울 & 울 & 울 & $\bar{i}$ & 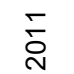 & $\bar{i}$ & $\bar{i}$ & $\bar{i}$ & $\stackrel{\bar{\sigma}}{\bar{j}}$ & $\stackrel{\bar{\Sigma}}{\bar{j}}$ & $\bar{i}$ & $\stackrel{\bar{\sigma}}{\bar{N}}$ & $\bar{i}$ \\
\hline 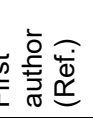 & 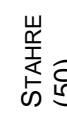 & & & & : & s) & 崫 & 岀 & 总 & 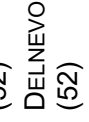 & 窇 & 总 & 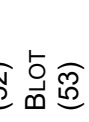 & 宮 \\
\hline 高 $\frac{0}{2}$ & $\stackrel{m}{\stackrel{m}{*}}$ & $\stackrel{m}{\leftarrow}$ & $\stackrel{m}{\sim}$ & $\stackrel{\circ}{\leftarrow}$ & 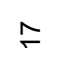 & 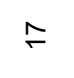 & $₹$ & $₹$ & $\stackrel{\infty}{\leftarrow}$ & $\stackrel{\infty}{\leftarrow}$ & $\stackrel{\infty}{\leftarrow}$ & $\stackrel{\infty}{\leftarrow}$ & $\check{\check{g}}$ & $\underset{\sigma}{\sigma}$ \\
\hline 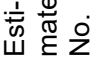 & $\stackrel{\varphi}{\circ}$ & $\stackrel{F}{\sim}$ & $\stackrel{\infty}{\sim}$ & $\stackrel{\rho}{\Gamma}$ & ని & $\bar{N}$ & N & $\stackrel{\infty}{N}$ & $\stackrel{d}{N}$ & $\stackrel{\mathscr{N}}{\sim}$ & $\stackrel{\mathscr{N}}{N}$ & $\hat{N}$ & $\stackrel{\infty}{N}$ & $\sim$ \\
\hline
\end{tabular}




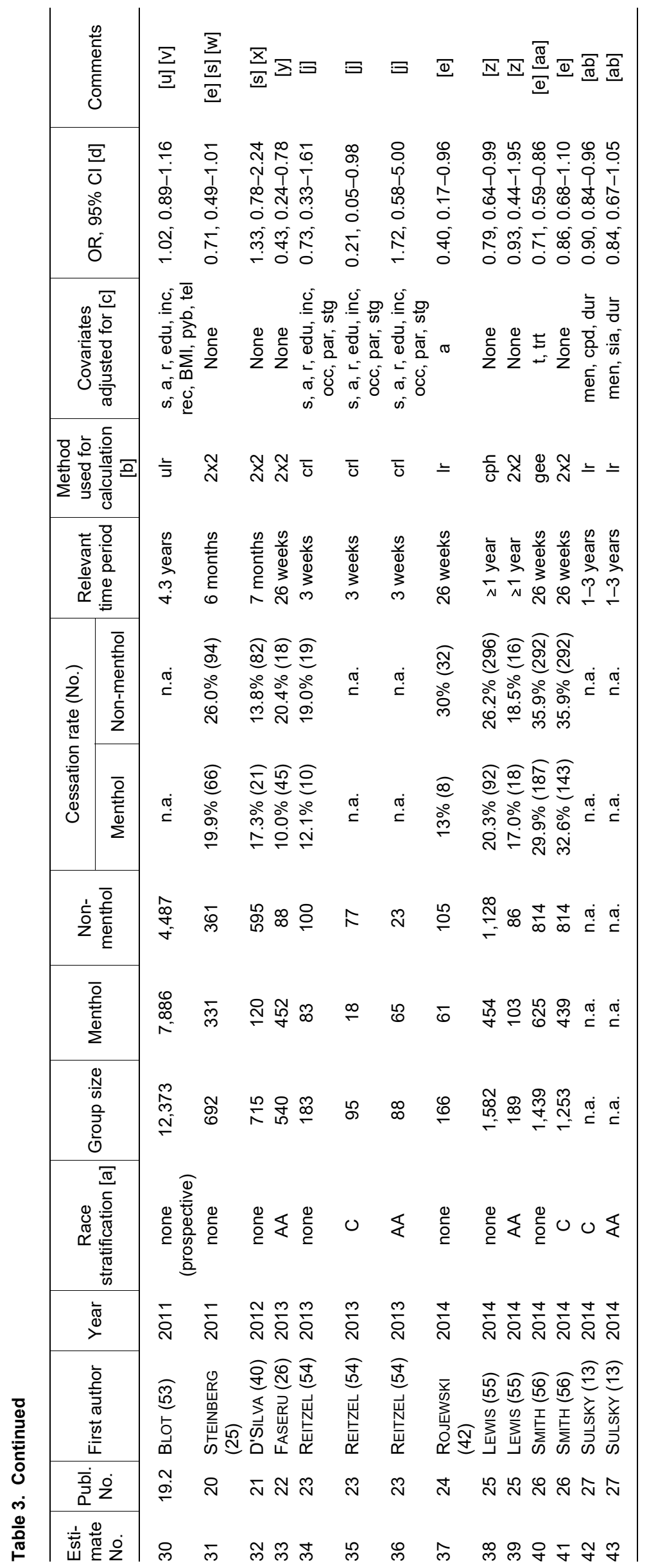




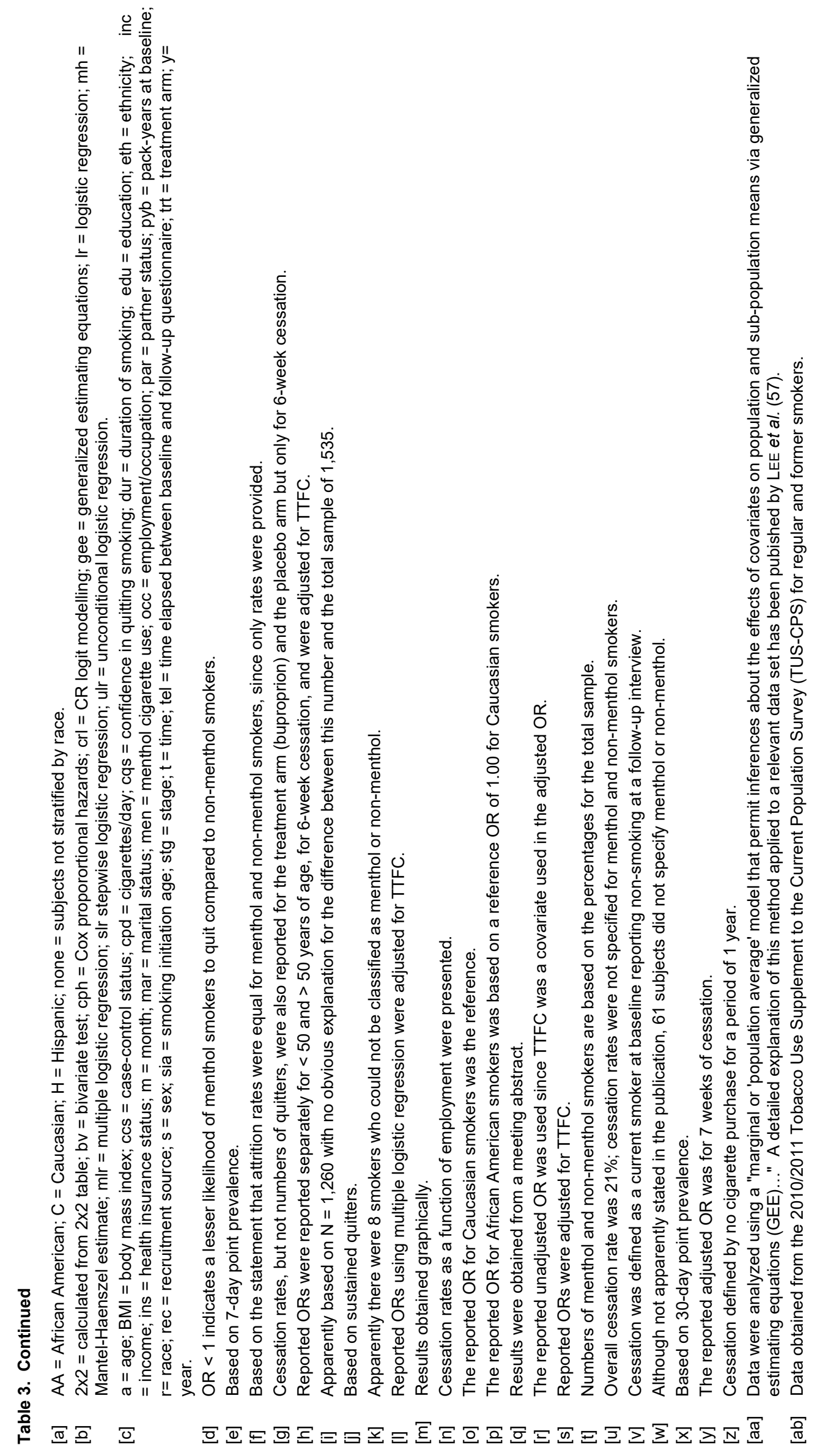


Table 4. Meta-analytic results for smoking cessation.

\begin{tabular}{lc|c|c}
\hline Description of group (N) & Fixed-effect OR (95\% CI) & Random-effects OR (95\% CI) $^{\text {a }}$ & I $^{\text {b }}$ \\
\hline Not stratified by race (30) & $0.96(0.94-0.99)$ & $0.87(0.80-0.96)$ & 84.24 \\
Caucasian (10) & $1.02(0.98-1.05)$ & $1.02(0.87-1.19)$ & 91.82 \\
African American (14) & $0.93(0.87-0.98)$ & $0.76(0.62-0.92)$ & 67.71 \\
Hispanic (4) & $0.91(0.79-1.04)$ & $0.85(0.63-1.14)$ & 42.12 \\
RCT study estimates (17) & $0.73(0.65-0.81)$ & $0.70(0.60-0.82)$ & 90.64 \\
Longitudinal and cross-sectional & $0.98(0.95-1.01)$ & $0.98(0.89-1.09)$ & \\
$\quad$ & & & \\
\hline
\end{tabular}

a $\mathrm{OR}>1$ indicates that menthol smokers are more likely to quit smoking than are non-menthol smokers

${ }^{b}$ Index of heterogeneity-attributable variance percent

and an association of $U$ and cessation of the same magnitude as the random-effects estimate of cigarette type on cessation. Similarly, the random-effects cessation estimate of 0.76 (95\% CI, 0.62-0.92) in African Americans would adjust away under the same assumptions, except that a $56 \%$ instead of a $55 \%$ prevalence of $U$ in menthol smokers would be required. In these scenarios, neither the prevalence of an unmeasured confounder $U$ in menthol and non-menthol cigarette smokers nor the magnitude of the association of $U$ and the respective outcome (TTFC or cessation) appear to be unrealistic.

Mechanistically, such a confounder would be associated with a simultaneous increased likelihood of smoking menthol rather than non-menthol cigarettes and smoking shortly after waking or finding it difficult to quit smoking. Race is a variable that would fit this description, based on the high prevalence of menthol cigarette use in African American smokers (3) and on a higher prevalence of smoking in this sociocultural subpopulation, although this difference is not large (14). However, even after conditioning the analyses on race (by stratification), cessation rates remain lower in African American menthol cigarette smokers compared to African American nonmenthol cigarette smokers. There appear to be only two explanations for this finding. The first is that there is an interaction between African American smokers and menthol cigarettes, perhaps genetic, which would make it more difficult for African American menthol cigarette smokers to quit. The second is that in addition to race, and possibly associated with it, residual confounding is operative in this subgroup. Such a residual confounder could be related to some socioeconomic, lifestyle, and/or cultural factor that could selectively affect certain subgroups of African American smokers. This is quite reasonable given the well-known inverse correlation of socioeconomic status (SES) and smoking cessation (15) as well as the fact that African Americans are more likely to be socially, economically, and educationally disadvantaged than are Caucasians (16). Such differences may also play a role with respect to smoking cessation of African American menthol cigarette smokers.

\section{Effect of residual confounding - results}

In order to evaluate empirically if SES may be playing a role as a confounder in the analyzed studies, stratification of cessation results based on presence or absence of adjustment for SES was conducted separately for all subjects, Caucasian subjects, African American subjects, RCT studies, and longitudinal and cross-sectional studies. Both adjusted and unadjusted results were available for certain estimates. However, in many cases only one type of estimate could be utilized. It is important to note that in no case was any estimate included where the results were adjusted for TTFC. The results of this analysis are presented in Table 5. As can be seen, not only does adjustment for SES provide results that are much closer to the null hypothesis than those that were not adjusted for SES (with the exception of the results for Caucasian smokers), but none of the adjusted estimates exhibited a statistically significant tendency for menthol cigarette smokers to find it more difficult to quit. The fixed-effect pooled estimates adjusted for SES for all subjects and Caucasian smokers, as well as results from longitudinal and cross-sectional studies indicate a statistically significantly greater ease of menthol cigarette smokers to quit as opposed to non-menthol cigarette smokers. Lastly, it should be noted that the adjusted pooled RCT ORs were no longer statistically significant; however, this result was based on only three estimates. Although not shown in Table 5, $\mathrm{I}^{2}$ values were calculated for all pooled ORs resulting from stratification based on SES factors. There was no material change in heterogeneity as a result of this stratification, meaning that SES factors are not the cause of the observed heterogeneity.

To further investigate the possible role that SES may be playing as a key residual confounder, baseline data were evaluated for each study used in the cessation metaanalyses in order to determine if there was indeed a tendency for menthol cigarette smokers to reflect lower SES "scores". These results are summarized in Table 6 for three SES factors; namely, education, employment, and income. With respect to education, 6 studies indicated that menthol cigarette smokers had less education than nonmenthol cigarette smokers (noted in bold), 2 studies indicated the opposite (noted in italics), whereas 4 studies showed no difference between the 2 types of smokers. Only 7 studies provided information relating to employment, with 4 showing that a greater number of non-menthol cigarette smokers were employed compared to menthol cigarette smokers, one showing the opposite, and 2 studies showing no difference. Lastly, 5 studies reported results on income, 2 of which indicated lesser earnings for menthol cigarette smokers and 3 of which indicated no difference. 
Table 5. Meta-analytic results for smoking cessation effect of adjustment for SES.

\begin{tabular}{lcc}
\hline Description of group (N) & Fixed-effect OR (95\% Cl) $^{\text {a }}$ & Random-effects OR (95\% Cl) $^{\text {a }}$ \\
\hline All (Table 4) (30) & $0.96(0.94-0.99)$ & $0.87(0.80-0.96)$ \\
All, adjusted for SES (10) & $1.03(1.00-1.07)$ & $1.06(0.90-1.24)$ \\
All, unadjusted for SES (25) & $0.80(0.78-0.82)$ & $0.76(0.67-0.87)$ \\
Caucasian (Table 4) (10) & $1.02(0.98-1.05)$ & $1.02(0.87-1.19)$ \\
Caucasian, adjusted for SES (5) & $1.07(1.03-1.12)$ & $1.14(0.83-1.55)$ \\
Caucasian, unadjusted for SES (8) & $0.95(0.93-0.98)$ & $0.93(0.76-1.13)$ \\
African American (Table 4) (14) & $0.93(0.87-0.98)$ & $0.76(0.62-0.92)$ \\
African American, adjusted for SES (7) & $1.00(0.94-1.07)$ & $1.02(0.95-1.09)$ \\
African American, unadjusted for SES (11) & $0.62(0.59-0.65)$ & $0.65(0.58-0.73)$ \\
RCT estimates (Table 4) (17) & $0.73(0.65-0.81)$ & $0.70(0.60-0.82)$ \\
RCT estimates, adjusted for SES (3) & $0.96(0.50-1.82)$ & $0.89(0.54-1.48)$ \\
RCT estimates, unadjusted for SES (15) & $0.71(0.64-0.78)$ & $0.69(0.59-0.81)$ \\
Long and CS estimates (Table 4) (13) & $0.98(0.95-1.01)$ & $0.98(0.89-1.09)$ \\
Long and CS estimates, adjusted for SES (7) & $1.03(1.00-1.07)$ & $1.06(0.90-1.25)$ \\
Long and CS estimates, unadjusted for SES (12) & $0.84(0.82-0.87)$ & $0.85(0.72-1.00)$ \\
\hline
\end{tabular}

a $\mathrm{OR}>1$ indicates that menthol smokers are more likely to quit smoking than are non-menthol smokers

Table 6. Comparison of SES factors menthol (M) and non-menthol (NM) smokers.

\begin{tabular}{|c|c|c|c|c|c|c|c|c|c|}
\hline \multirow{2}{*}{ Study } & \multicolumn{3}{|c|}{ Measure of education } & \multicolumn{3}{|c|}{ Measure of employment } & \multicolumn{3}{|c|}{ Measure of income } \\
\hline & $\% \mathrm{M}$ & $\%$ NM & $p$ & $\% \mathrm{M}$ & $\% N M$ & $p$ & $\% \mathrm{M}$ & $\% \mathrm{NM}$ & $p$ \\
\hline \multirow[t]{2}{*}{ OKUYEMI, 2003 (31) } & \multicolumn{3}{|c|}{$\geq$ High school graduate } & \multicolumn{3}{|c|}{ Employed } & \multicolumn{3}{|c|}{ Monthly income $>\$ 1,800$} \\
\hline & $50.7 \%$ & $47.3 \%$ & $p=0.487$ & $78.3 \%$ & $65.9 \%$ & $p=0.004$ & $45.4 \%$ & $45.3 \%$ & $p=0.977$ \\
\hline \multirow[t]{2}{*}{ PletCheR, 2006 (46) } & \multicolumn{3}{|c|}{ Some college } & \multicolumn{3}{|c|}{ Employed full time } & \multicolumn{3}{|c|}{$\mathrm{NS}^{\mathrm{a}}$} \\
\hline & $35.3 \%$ & $53.5 \%$ & $p<0.001$ & $45.5 \%$ & $62.2 \%$ & $\mathrm{p}<0.001$ & & & \\
\hline \multirow[t]{2}{*}{ OKUYEMI, 2007 (47) } & \multicolumn{3}{|c|}{$\geq$ High school education } & \multicolumn{3}{|c|}{ Employed } & \multicolumn{3}{|c|}{ Monthly income $>\$ 1,800$} \\
\hline & $83.2 \%$ & $84.8 \%$ & $p=0.705$ & $47.5 \%$ & $49.3 \%$ & $p=0.707$ & $40.4 \%$ & $43.9 \%$ & $p=0.494$ \\
\hline \multirow[t]{2}{*}{ MURRAY, 2007 (48) } & \multicolumn{3}{|c|}{ Education (years) } & \multirow{2}{*}{\multicolumn{3}{|c|}{ NS }} & \multirow{2}{*}{\multicolumn{3}{|c|}{ NS }} \\
\hline & $13.8 \%$ & $13.6 \%$ & & & & & & & \\
\hline \multirow[t]{2}{*}{ Fu, 2008 (33) } & \multicolumn{3}{|c|}{ Some college or more } & \multirow{2}{*}{\multicolumn{3}{|c|}{ NS }} & \multirow{2}{*}{\multicolumn{3}{|c|}{ NS }} \\
\hline & $61 \%$ & $39 \%$ & $p<0.001$ & & & & & & \\
\hline \multirow[t]{2}{*}{ GANDHI, 2009 (34) } & \multicolumn{3}{|c|}{ Bachelors or higher } & \multicolumn{3}{|c|}{ Employed full time } & \multicolumn{3}{|c|}{ NS } \\
\hline & $14.9 \%$ & $30.8 \%$ & $p<0.001$ & $41.2 \%$ & $48.8 \%$ & $p<0.001$ & & & \\
\hline \multirow[t]{2}{*}{ STAHRE, 2010 (50) } & \multicolumn{3}{|c|}{ Some college/degree } & & NS & & & NS & \\
\hline & $38.7 \%^{b}$ & $44.3 \%^{b}$ & $p=0.025$ & & & & & & \\
\hline REITZEL, 2011 (39) & & h school & & & NS & & & $20,000 / y$ & \\
\hline & $23.6 \%$ & $13.2 \%$ & $p=0.037$ & & & & $56.0 \%$ & $75.9 \%$ & $p=0.002$ \\
\hline DELNEVo, 2011 (52) & & /BS or $\mathrm{m}$ & & & NS & & & $75,000 / y$ & \\
\hline & $15.4 \%$ & $11.1 \%$ & & & & & $15.2 \%$ & $18.6 \%$ & \\
\hline D'SILVA, 2012 (40) & & han high & hool & & NS & & & NS & \\
\hline & $14.4 \%$ & $8.9 \%$ & & & & & & & \\
\hline REITZEL, 2013 (54) & & school d & oma & & Employed & & & $20,000 / y$ & \\
\hline & $60.2 \%$ & $73.0 \%$ & $p=0.067$ & $43.4 \%$ & $58.0 \%$ & $p=0.049$ & $47.5 \%$ & $58.6 \%$ & $p=0.14$ \\
\hline ROJEWSKI, 2014 (42) & & NS & & & Employed & & & NS & \\
\hline & & & & $78.7 \%$ & $80.0 \%$ & & & & \\
\hline SMITH, 2014 (56) & & school d & oma & & Employed & & & NS & \\
\hline & $63.9 \%$ & $76.9 \%$ & $p<0.0001^{c}$ & $75.8 \%$ & $80.2 \%$ & $p=0.0056^{c}$ & & & \\
\hline
\end{tabular}

a Not specified

${ }^{b}$ For current smokers

${ }^{c} \mathrm{p}$ value for group difference 
These results, although not unidirectional, show that menthol cigarette smokers are more likely to have lower SES "scores" than non-menthol cigarette smokers.

Stratification based on adjustment for SES was also carried out for large studies that investigated the relationship of menthol cigarette smoking with respect to TTFC. Only large studies were investigated, since no small study had results that were adjusted for SES. The effect of adjustment of TTFC for SES moved the results in the opposite direction than those obtained for cessation. The pooled fixed-effect OR for the six adjusted estimates was 1.10 (95\% CI, 1.03-1.17) and the random-effects TTFC OR was 1.11 (95\% CI, 1.04-1.19). The seven unadjusted estimates gave results of $1.04(95 \% \mathrm{CI}, 1.01-1.07)$ and 1.02 (95\% CI, 0.92-1.13), respectively. Although adjustment for SES resulted in a directional increase in menthol cigarette smokers smoking their first cigarette within the first $5 \mathrm{~min}$ of waking, the difference was not statistically significant with $\mathrm{p}=0.12$ for the two fixed-effect estimates and $\mathrm{p}=0.21$ for the random-effects estimates.

\section{DISCUSSION}

The major strengths of this analysis are: 1) a comprehensive literature search was conducted that appears to have identified all relevant published studies, and 2) a quantitative analysis was undertaken.

The results of these meta-analyses without inclusion of confounding by SES are quite consistent with the qualitative analysis conducted by the FDA (3); namely, that menthol cigarette smokers are more likely to smoke their first cigarette of the day earlier than non-menthol cigarette smokers, while African American menthol cigarette smokers are more likely to find it difficult to quit smoking as compared to African American non-menthol cigarette smokers. However, comparison of cessation studies that adjusted for SES compared to those that did not make this adjustment showed no statistically significant difference for African American menthol and non-menthol smokers. On the other hand adjustment of TTFC for SES factors slightly increased the difference between menthol and non-menthol cigarette smokers. As a consequence, it is of interest to examine more closely the claim that TTFC is a valid marker of ease of smoking cessation.

The FDA (3) suggested that TTFC is the best measure of nicotine dependence primarily based on a study by BAKER et al. (17). These authors indicated that the specific question regarding TTFC in the FTND (question 1) was the best predictor of smoking cessation success at both 1 week and 6 months in 5 US studies. In addition they reported that smokers whose TTFC was $<5$ min were more likely to experience difficulty in quitting than those whose TTFC was between 5 and $30 \mathrm{~min}$. It should be noted that none of these studies compared cessation results separately for menthol and non-menthol cigarette smokers.

There are other studies that have confirmed the positive relationship between TTFC and successful smoking cessation. HADDOCK et al. (18) reported that the TTFC question in the FTND was strongly related to 1 year of smoking cessation. TOLL et al. (19) suggested that TTFC was strongly related to cigarette craving, and that craving, in turn, was a strong predictor of the tendency of smokers to relapse following cessation. SWEITZER et al. (20) reported that TTFC was significantly associated with success rate in a smoking cessation trial (hazard ratio $[\mathrm{HR}]=6.97,95 \% \mathrm{CI}, 1.67-29.12)$, although the length of this trial was only 8 days.

Other published results, however, call into question the value of TTFC as a predictor of smoking cessation, particularly with respect to longer-term smoking cessation. Based on the HSI, which is composed of TTFC and cigarettes per day (CPD), FIDLER et al. (21) found only a weak association with 6-month smoking cessation rates $(\mathrm{OR}=1.21,95 \% \mathrm{CI}, 1.07-1.38)$. Moreover, after adjusting for urge to smoke, the relationship was no longer statistically significant $(\mathrm{OR}=1.11,95 \% \mathrm{CI}, 0.97-1.28)$. COURVOISIER and ETTER (22) reported that although the HSI was a significant predictor of success of smoking cessation at 8 days, this index could explain only $1-3 \%$ of the variance in smoking cessation at 31 days. A recent paper similarly suggested a lack of correlation between TTFC and smoking cessation for longer cessation periods (23). This study indicated a significant association between TTFC and short-term smoking abstinence (7- or 14-days), which was considerably reduced and no longer significant for 30-day smoking abstinence. It should be noted that all subjects suffered from substance use disorder, although this seems unlikely to have affected the association between TTFC and smoking cessation.

The above discussion suggests that any direct correlation between TTFC and smoking cessation results may be attenuated as the time of cessation increases.

The evidence that TTFC may not be effective in predicting long-term smoking cessation coupled with the generally very small difference obtained herein with respect to the association of TTFC and menthol cigarette smoking may at least partially explain some of the inconsistencies in the analyses on cessation (see Table 4). For example, the differences in findings between the large longitudinal or cross-sectional studies and smaller RCT studies may be explained in part by the difference in smoking cessation periods, with RCT studies tending to look at cessation at 6 months, whereas longitudinal and cross-sectional studies tend to look at longer-term cessation.

It should be noted that while small studies usually randomly allocated smokers to different types of interventions for cessation, this randomization does not extend to menthol and non-menthol cigarette smokers. This implies that the analysis conducted here, which looks at differences between menthol and non-menthol cigarette smokers, is not protected for imbalance of baseline covariates by randomization. Thus, small studies, even though originally set up as RCTs, should be considered as simply observational studies in the context of the present analysis, albeit they are usually smaller than studies that have been classified as observational studies by design. It should also be noted that the majority of the studies on African American populations in the meta-analysis for smoking cessation were based on RCT studies. This may provide some explanation for the observed difference in smoking cessation rates between menthol and non-menthol cigarette smokers for this group. A meta-analysis restricted to only African American subjects in longitudinal and 
cross-sectional studies (estimates 2, 17, 26, 29, and 43) gave a fixed-effect result $(\mathrm{OR}=0.95,95 \% \mathrm{CI}, 0.89-1.01)$. Although this result was only slightly higher than the fixedeffect result for all African American subjects $(\mathrm{OR}=0.93$, 95\% CI, 0.87-0.98), the result was no longer statistically significant.

The result of the investigation of the possible impact of socioeconomic effects with respect to smoking cessation merits further discussion. Three RCT studies provide further support for the importance of adjustment for SES factors. FOULDS et al. (24) indicated that the OR for successful cessation at 26 weeks for smokers with some college/technical school education was $1.38(\mathrm{p}=0.092)$, while for smokers with a bachelor's degree or higher the OR was $1.65(\mathrm{p}=0.02)$ compared to less than high school, high school, or General Educational Development (GED) test as the reference value. STEINBERG et al. (25) reported that the OR for successful cessation at 6 months for unemployed smokers was 0.45 (95\% CI, 0.25-0.80) compared to employed smokers. They also provide information on the association of successful cessation with educational attainment, but the results were mixed, and none of the ORs were statistically significant. FASERU et al. (26) reported that $14.1 \%$ of smokers earning $\geq \$ 1,800 /$ month successfully quit compared to $10.1 \%$ of smokers earning less than that amount, but this result was not statistically significant $(p=0.15)$. These results add further support to the importance of SES factors playing a key role with respect to smoking cessation.

One major weakness of this analysis is that the results are based on the pooling of numerous different types of studies, and there are insufficient data to stratify the data optimally. In addition, there are wide differences in the extent to which the included studies have been adjusted for covariates, ranging from completely unadjusted estimates to estimates adjusted for numerous covariates. This point is particularly important when considering the findings comparing studies adjusted for SES factors and those that were not. This difference could reflect adjustment for other confounders. An indication that many different types of studies have been pooled is clearly illustrated by the high levels of heterogeneity present in all of the meta-analyses. Given the high level of heterogeneity present in virtually all of the pooled estimates, it would not have been unreasonable to have presented only the results from the random-effects analyses. However, in presenting both types of pooled ORs in Tables 2, 4, and 5, it can be seen that the fixed-effect and random-effects estimates are invariably in very good agreement, with the exception of the African American cessation results (Table 4). This suggests that the high level of heterogeneity was not a major factor with respect to the pooled estimates. It should also be noted that stratifying both the TTFC (time period, study size) and cessation (race, study type, SES) results on all reasonable factors, given the available data, did not materially reduce the heterogeneity, meaning that we were unable to identify the source of the heterogeneity. It would be ideal if the pooled raw data could have been analyzed using multiple logistic regression, thereby allowing the contribution of covariates to the pooled estimates to be determined; however, the required data were not available.

With respect to adjustment for smoking cessation studies, the decision was made to not include estimates that were adjusted for TTFC or a surrogate for TTFC (FTND or HSI) in order to avoid an over-adjusted model. Meta-analyses conducted with these studies included indicated that the differences between the two sets of results were negligible (data not shown). Arguably other factors related to nicotine dependence could also lead to over-adjustment. For example some studies also adjusted for CPD (estimates 1, 2, and 42), duration of smoking (estimates 1, 2, 42, and 43), pack years at baseline (estimate 30 ) and confidence in quitting smoking (estimates 6 and 7). In the case of CPD, the FDA report (3) took the position that smoking restrictions have led to this marker being less reliable as a measure of dependence, although BAKER et al. (17) reported mixed results for the association of CPD with smoking cessation. Given that only 3 estimates in the data set were corrected for CPD, and that there is some question as to the importance of CPD as a marker of dependence, it was decided to retain these three estimates. With respect to duration of smoking, SWEITZER et al. (20) examined the association between years of smoking and time to first relapse and reported an OR of 1.07 (95\% CI, 1.00-1.14). Given the weakness of this association it was felt appropriate to retain the estimates that adjusted for this covariate. There is little information in the literature regarding "confidence in quitting smoking" and successful quitting. Two studies have been published reporting that individuals who have a high level of confidence with respect to quitting smoking are more likely to be successful $(27,28)$. On the other hand, confidence in quitting was closely related to "self-efficacy" (29), which has been extensively investigated. In a meta-analysis by GWALTNEY et al. (30), all published results through 2006, consisting of 189 analyses drawn from 54 publications, were pooled and it was concluded that "the relationship between $S E$ [selfefficacy] and subsequent smoking was reliable and statistically significant, but small, accounting for only $2 \%$ of the variance in outcome...". Furthermore, the outcome was substantially lower among studies examining a pre-quit self-efficacy measure, which was the case for the two estimates included in this meta-analysis. As a consequence, these two estimates were retained.

\section{CONCLUSIONS}

In conclusion, meta-analysis of the available data on TTFC and menthol cigarette smokers indicates a weak association between menthol cigarette smoking and shorter TTFC. There is clearly a significant difference in small studies indicating that menthol smokers are more likely to have a shorter TTFC than are non-menthol cigarette smokers, but this is not the case in large studies. Inconsistencies exist with respect to the cessation results. There was no difference between Caucasian menthol and non-menthol smokers. On the other hand African American menthol cigarette smokers were less likely to quit smoking than were African American non-menthol cigarette smokers. In this case both the fixed-effect and random-effects estimates were statistically significant. The results of these metaanaylses for cessation tend to support the results of other research cited above suggesting that TTFC is not a 
meaningful indicator for the ability to quit smoking. It appears possible, however, that the difference for cessation between the two races is attributable to residual confounding. Not only are the SES-adjusted pooled ORs for African American menthol cigarette smokers essentially equal to 1 , but there is no longer a statistically significant difference between the pooled adjusted ORs for African Americans and Caucasians. On the other hand, the very high heterogeneity observed in virtually all of the metaanalyses conducted in this study strongly suggests that key potential confounding factors have not yet been identified and adjusted for. As a consequence, further detailed research is still necessary to fully determine if there is indeed any difference between menthol and non-menthol cigarette smokers with respect to smoking cessation.

\section{CONFLICT OF INTEREST}

R.D. and R.W. are employees of Philip Morris International. E.S. is a scientific consultant and former employee of Philip Morris International.

\section{ACKNOWLEDGMENTS}

The authors would like to thank Mr. Peter N. Lee for helpful assistance with respect to the statistical analysis as well as helpful discussions. The authors would also like to thank Mme. Simone Pfändler for assistance with respect to the correct transfer of the results to the tables.

\section{REFERENCES}

1. U.S. Department of Health and Human Services, Centers for Disease Control and Prevention, National Center for Chronic Disease Prevention and Health Promotion, Office on Smoking and Health: How Tobacco Smoke Causes Disease: The Biology and Behavioral Basis for Smoking-Attributable Disease. A Report of the Surgeon General; Atlanta, GA, USA, 2010.

2. Fagerström, K.: The Epidemiology of Smoking: Health Consequences and Benefits of Cessation; Drugs 62 (Suppl. 2) (2002) 1-9.

3. Food and Drug Administration (FDA): Reference Addendum: Preliminary Scientific Evaluation of the Possible Public Health Effects of Menthol Versus Nonmenthol Cigarettes; 2013. Available at: http://www.fda.gov/downloads/ScienceResearch/Spe cialTopics/PeerReviewofScientificInformationandAs sessments/UCM362600.pdf (accessed November 2016).

4. Foulds, J., M.W. Hooper, M.J. Pletcher, and K.S. Okuyemi: Do Smokers of Menthol Cigarettes Find it Harder to Quit Smoking?; Nicotine Tob. Res. 12 (S2) (2010) S102-S109. DOI: 10.1093/ntr/ntq166

5. Hoffman, A.C. and D. Miceli: Menthol Cigarettes and Smoking Cessation Behavior; Tob. Induc. Dis. 9 (S1) (2011) S6. DOI: 10.1186/1617-9625-9-S1-S6

6. Heatherton, T.F., L.T. Kozlowski, R.C. Frecker, W.
Rickert, and J. Robinson: Measuring the Heaviness of Smoking: Using Self-Reported Time to the First Cigarette of the Day and Number of Cigarettes Smoked per Day; Br. J. Addict. 84 (1989) 791-799.

7. Heatherton, T.F., L.T. Kozlowski, R.C. Frecker, and K.O. Fagerström: The Fagerström Test for Nicotine Dependence: A Revision of the Fagerström Tolerance Questionnaire; Br. J. Addict. 86 (1991) 1119-1127.

8. Weitkunat, R. and M. Wildner: Exploratory Causal Modeling in Epidemiology: Are All Factors Created Equal?; J. Clin. Epidemiol. 55 (2002) 436-444.

9. Schisterman, E.F., S.R. Cole, and R.W. Platt: Overadjustment Bias and Unnecessary Adjustment in Epidemiologic Studies; Epidemiology 20 (2009) 488-495. DOI: 10.1097/EDE.0b013e3181a819a1

10. Normand, S.L.: Meta-Analysis: Formulating, Evaluating, Combining, and Reporting; Stat. Med. 18 (1999) 321-359.

11. VanderWeele, T.J. and O.A. Arah: Bias Formulas for Sensitivity Analysis of Unmeasured Confounding for General Outcomes, Treatments, and Confounders; Epidemiology 22 (2011) 42-52.

DOI: 10.1097/EDE.0b013e3181f74493

12. Hyland, A., S. Garten, G.A. Giovino, and K.M. Cummings: Mentholated Cigarettes and Smoking Cessation: Findings from COMMIT. Community Intervention Trial for Smoking Cessation; Tob. Control 11 (2002) 135-139.

13. Sulsky, S.I., W.G. Fuller, C. Van Landingham, M.W. Ogden, J.E. Swauger, and G.M. Curtin: Evaluating the Association between Menthol Cigarette Use and the Likelihood of Being a Former versus Current Smoker; Regul. Toxicol. Pharmacol. 70 (2014) 231-241. DOI: 10.1016/j.yrtph.2014.07.009

14. Cokkinides, V., P. Bandi, C. McMahon, A. Jemal, T. Glynn, and E. Ward: Tobacco Control in the United States - Recent Progress and Opportunities; CA Cancer J. Clin. 59 (2009) 352-365. DOI: 10.3322/caac.20037

15. Reid, J.L., D. Hammond, C. Boudreau, G.T. Fong, M. Siahpush, and ITC Collaboration: Socioeconomic Disparities in Quit Intentions, Quit Attempts, and Smoking Abstinence among Smokers in Four Western Countries: Findings from the International Tobacco Control Four Country Survey; Nicotine Tob. Res. 12 (Suppl.) (2010) S20-S33. DOI: 10.1093/ntr/ntq051

16. Dimou, A., K.N. Syrigos, and M.W. Saif: Disparities in Colorectal Cancer in African-Americans vs Whites: Before and after Diagnosis; World J. Gastroenterol. 15 (2009) 3734-3743. DOI: 10.3748/wjg.15.3734

17. Baker, T.B., M.E. Piper, D.E. McCarthy, D.M. Bolt, S.S. Smith, S.-Y. Kim, S. Colby, D. Conti, G.A. Giovino, D. Hatsukami, A. Hyland, S. Krishnan-Sarin, R. Niaura, K.A. Perkins, and B.A. Toll: Time to First Cigarette in the Morning as an Index of Ability to Quit Smoking: Implications for Nicotine Dependence; Nicotine Tob. Res. 9 (Suppl. 4) (2007) S555-S570. DOI: $10.1080 / 14622200701673480$

18. Haddock, C.K., H. Lando, R.C. Klesges, G.W. Talcott, and E.A. Renaud: A Study of the Psychometric and Predictive Properties of the Fagerström Test for Nicotine Dependence in a Population of Young Smokers; Nicotine Tob. Res. 1 (1999) 59-66. 
19. Toll, B.A., T.S. Schepis, S.S. O’Malley, S.A. McKee, and S. Krishnan-Sarin: Subjective Reactivity to the First Cigarette of the Day as a Predictor of Smoking Relapse: A Preliminary Study; Drug Alcohol Depend. 89 (2007) 302-305.

20. Sweitzer, M.M., R.L. Denlinger, and E.C. Donny: Dependence and Withdrawal-Induced Craving Predict Abstinence in an Incentive-Based Model of Smoking Relapse; Nicotine Tob. Res. 15 (2013) 36-43. DOI: $10.1093 /$ ntr/nts080

21. Fidler, J.A., L. Shahab, and R. West: Strength of Urges to Smoke as a Measure of Severity of Cigarette Dependence: Comparison with the Fagerström Test for Nicotine Dependence and its Components; Addiction 106 (2011) 631-638.

DOI: $10.1111 /$ j.1360-0443.2010.03226.x

22. Courvoisier, D.S. and J.F. Etter: Comparing the Predictive Validity of Five Cigarette Dependence Questionnaires; Drug Alcohol Depend. 107 (2010) 128-133. DOI: 10.1016/j.drugalcdep.2009.09.011

23. Rohsenow, D.J., R.A. Martin, J.W. Tidey, P.M. Monti, and S.M. Colby: Comparison of the Cigarette Dependence Scale with Four Other Measures of Nicotine Involvement: Correlations with Smoking History and Smoking Treatment Outcome in Smokers with substance Use Disorders; Addict. Behav. 38 (2013) 2409-2413.

DOI: 10.1016/j.addbeh.2013.03.019

24. Foulds, J., K.K. Gandhi, M.B. Steinberg, D.L. Richardson, J.M. Williams, M.V. Burke, and G.G. Rhoads: Factors Associated with Quitting Smoking at a Tobacco Dependence Treatment Clinic; Am. J. Health Behav. 30 (2006) 400-412.

25. Steinberg, M.B., M.T. Bover, D.L. Richardson, A.C. Schmelzer, J.M. Williams, and J. Foulds: Abstinence and Psychological Distress in Co-Morbid Smokers Using Various Pharmacotherapies; Drug Alcohol Depend. 114 (2011) 77-81.

DOI: 10.1016/j.drugalcdep.2010.06.022

26. Faseru, B., N.L. Nollen, M.S. Mayo, R. Krebill, W.S. Choi, N.L. Benowitz, R.F. Tyndale, K.S. Okuyemi, J.S. Ahluwalia, and L. Sanderson Cox: Predictors of Cessation in African American Light Smokers Enrolled in a Bupropion Clinical Trial: Addict. Behav. 38 (2013) 1796-1803.

DOI: 10.1016/j.addbeh.2012.11.010

27. Marino, M.G., E. Fusconi, R. Magnatta, A. Panà, and M. Maurici: Epidemiologic Determinants Affecting Cigarette Smoking Cessation: A Retrospective Study in a National Health System (SSN) Treatment Service in Rome (Italy); J. Environ. Public Health 2010 (2010) 183206. DOI: $10.1155 / 2010 / 183206$

28. Khan, N., J.R. Anderson, J. Du, D. Tinker, A.M Bachyrycz, and R. Namdar: Smoking Cessation and its Predictors: Results from a Community-Based Pharmacy Tobacco Cessation Program in New Mexico; Ann. Pharmacother. 46 (2012) 1198-1204.

DOI: 10.1345/aph.1P146

29. Etter, J.F., M.M. Bergman, J.P. Humair, and T.V. Perneger: Development and Validation of a Scale Measuring Self-Efficacy of Current and Former Smokers; Addiction 95 (2000) 901-913.
30. Gwaltney, C.J., J. Metrik, C.W. Kahler, and S. Shiffman: Self-Efficacy and Smoking Cessation: A Meta-Analysis; Psychol. Addict. Behav. 23 (2009) 56-66. DOI: 10.1037/a0013529

31. Okuyemi, K.S., J.S. Ahluwalia, M. Ebersole-Robinson, D. Catley, M.S. Mayo, and K. Resnicow: Does Menthol Attenuate the Effect of Bupropion Among African American Smokers?; Addiction 98 (2003) 1387-1393.

32. Collins, C.C. and E.T. Moolchan: Shorter Time to First Cigarette of the Day in Menthol Adolescent Cigarette Smokers; Addict. Behav. 31 (2006) 1460-1464.

33. Fu, S.S., K.S. Okuyemi, M.R. Partin, J.S. Ahluwalia, D.B. Nelson, B.A. Clothier, and A.M. Joseph: Menthol Cigarettes and Smoking Cessation During an Aided Quit Attempt; Nicotine Tob. Res. 10 (2008) 457-462. DOI: $10.1080 / 14622200801901914$

34. Gandhi, K.K., J. Foulds, M.B. Steinberg, S.E. Lu, and J.M. Williams: Lower Quit Rates Among African American and Latino Menthol Cigarette Smokers at a Tobacco Treatment Clinic; Int. J. Clin. Pract. 63 (2009) 360-367. DOI: 10.1111/j.1742-1241.2008.01969.x

35. Muscat, J.E., G. Chen, A. Knipe, S.D. Stellman, P. Lazarus, and J.P. Richie Jr: Effects of Menthol on Tobacco Smoke Exposure, Nicotine Dependence, and NNAL Glucuronidation; Cancer Epidemiol. Biomarkers Prev. 18 (2009) 35-41. DOI: 10.1158/1055-9965.EPI-08-0744

36. Fagan, P., E.T. Moolchan, A. Hart Jr, A. Rose, D. Lawrence, V.L. Shavers, and J.T. Gibson: Nicotine Dependence and Quitting Behaviors Among Menthol and Non-Menthol Smokers with Similar Consumptive Patterns; Addiction 105 (S1) (2010) 55-74. DOI: $1111 / \mathrm{j} .1360-0443.2010 .03190 . \mathrm{x}$

37. Ahijevych, K. and J. Ford: The Relationships between Menthol Cigarette Preference and State Tobacco Control Policies on Smoking Behaviors of Young Adult Smokers in the 2006-07 Tobacco Use Supplements to the Current Population Surveys (TUS CPS); Addiction 105 (S1) (2010) 46-54. DOI: $10.1111 /$ j.1360-0443.2010.03201.x

38. Faseru, B., W.S. Choi, R. Krebill, M.S. Mayo, N.L. Nollen, K.S. Okuyemi, J.S. Ahluwalia, and L.S. Cox: Factors Associated with Smoking Menthol Cigarettes Among Treatment-Seeking African American Light Smokers; Addict. Behav. 36 (2011) 1321-1324. DOI: 10.1016/j.addbeh.2011.07.015

39. Reitzel, L.R., N. Nguyen, Y. Cao, J.I. Vidrine, P. Daza, P.D. Mullen, M.M. Velasquez, Y. Li, P.M. Cinciripini, L. Cofta-Woerpel, and D.W. Wetter: Race/Ethnicity Moderates the Effect of Prepartum Menthol Cigarette Use on Postpartum Smoking Abstinence; Nicotine Tob. Res. 13 (2011) 1305-1310. DOI: 10.1093/ntr/ntr095

40. D'Silva, J., R.G. Boyle, R. Lien, P. Rode, and K.S. Okuyemi: Cessation Outcomes Among Treatment-Seeking Menthol and Nonmenthol Smokers; Am. J. Prev. Med. 43 (S3) (2012) S242-S248.

DOI: 10.1016/j.amepre.2012.07.033

41. Rosenbloom, J., V.W. Rees, K. Reid, J. Wong, and T. Kinnunen: A Cross-Sectional Study on Tobacco Use and Dependence Among Women: Does Menthol Matter?; Tob. Induc. Dis. 10 (2012) 19. 
DOI: $10.1186 / 1617-9625-10-19$

42. Rojewski, A.M., B.A. Toll, and S.S. O’Malley: Menthol Cigarette Use Predicts Treatment Outcomes of Weight-Concerned Smokers; Nicotine Tob. Res. 16 (2014) 115-119. DOI: 10.1093/ntr/ntt137

43. Frost-Pineda, K., R. Muhammad-Kah, L. Rimmer, and Q. Liang: Predictors, Indicators, and Validated Measures of Dependence in Menthol Smokers; J. Addict. Dis. 33 (2014) 94-113. DOI: $10.1080 / 10550887.2014 .909696$

44. Curtin, G.M., S.I. Sulsky, C. Van Landingham, K.M. Marano, M.J. Graves, M.W. Ogden, and J.E. Swauger: Primary Measures of Dependence Among Menthol Compared to Non-Menthol Cigarette Smokers in the United States; Regul. Toxicol. Pharmacol. 69 (2014) 451-466. DOI: 10.1016/j.yrtph.2014.05.011

45. Muscat, J.E., J.P. Richie Jr, and S.D. Stellman: Mentholated Cigarettes and Smoking Habits in Whites and Blacks; Tob. Control 11 (2002) 368-371.

46. Pletcher, M.J., B.J. Hulley, T. Houston, C.I. Kiefe, N. Benowitz, and S. Sidney: Menthol Cigarettes, Smoking Cessation, Atherosclerosis, and Pulmonary Function: The Coronary Artery Risk Development in Young Adults (CARDIA) Study; Arch. Intern. Med. 166 (2006) 1915-1922.

DOI: 10.1001/archinte.166.17.1915

47. Okuyemi, K.S., B. Faseru, L. Sanderson Cox, C.A. Bronars, and J.S. Ahluwalia: Relationship Between Menthol Cigarettes and Smoking Cessation Among African American Light Smokers; Addiction 102 (2007) 1979-1986.

48. Murray, R.P., J.E. Connett, M.A. Skeans, and D.P. Tashkin: Menthol Cigarettes and Health Risks in Lung Health Study Data; Nicotine Tob. Res. 9 (2007) 101-107.

49. Cropsey, K.L., M.F. Weaver, G.D. Eldridge, G.C. Villalobos, A.M. Best, and M.L. Stitzer: Differential Success Rates in Racial Groups: Results of a Clinical Trial of Smoking Cessation Among Female Prisoners; Nicotine Tob. Res. 11 (2009) 690-697. DOI: $10.1093 /$ ntr/ntp051

50. Stahre, M., K.S. Okuyemi, A.M. Joseph, and S.S. Fu: Racial/Ethnic Differences in Menthol Cigarette Smoking, Population Quit Ratios and Utilization of Evidence-Based Tobacco Cessation Treatments; Addiction 105 (S1) (2010) 75-83. DOI: $10.1111 /$ j.1360-0443.2010.03200.x

51. Rose, J.E. and F. Behm: Menthol Smokers, SES and Quit-Smoking Outcome; Society for Research on Nicotine and Tobacco Conference, Baltimore, MD, USA, February 24-27, 2010; Abstract POS5-58. Available at: https://c.ymcdn.com/sites/ srnt.site-ym.com/resource/resmgr/Conferences/Past Annual_Meetings/2010_Annual_Meeting_Abstract.pdf (Accessed November 2016).

52. Delnevo, C.D., D.A. Gundersen, M. Hrywna, S.E. Echeverria, and M.B. Steinberg: Smoking-Cessation Prevalence Among U.S. Smokers of Menthol versus Non-Menthol Cigarettes; Am. J. Prev. Med. 41 (2011) 357-365. DOI: 10.1016/j.amepre.2011.06.039

53. Blot, W.J., S.S. Cohen, M. Aldrich, J.K. McLaughlin, M.K. Hargreaves, and L.B. Signorello: Lung Cancer
Risk Among Smokers of Menthol Cigarettes; J. Natl. Cancer Inst. 103 (2011) 810-816.

DOI: $10.1093 /$ jnci/djr102

54. Reitzel, L.R., Y. Li, D.W. Stewart, Y. Cao, D.W. Wetter, A.J. Waters, and J.I. Vidrine: Race Moderates the Effect of Menthol Cigarette Use on Short-Term Smoking Abstinence; Nicotine Tob. Res. 15 (2013) 883-889. DOI: $10.1093 /$ ntr/nts335

55. Lewis, M., Y. Wang, and C.J. Berg: Tobacco Control Environment in the United Sates and Individual Consumer Characteristics in Relation to Continued Smoking: Differential Responses Among Menthol Smokers?; Prev. Med. 65 (2014) 47-51. DOI: 10.1016/j.ypmed.2014.04.019

56. Smith, S.S., M.C. Fiore, and T.B. Baker: Smoking Cessation in Smokers who Smoke Menthol and Non-Menthol Cigarettes; Addiction 109 (2014) 2107-2117. DOI: 10.1111/add.12661

57. Lee, J.H., T.A. Herzog, C.D. Meade, M.S. Webb, and T.H. Brandon: The Use of GEE for Analyzing Longitudinal Binomial Data: A Primer Using Data from a Tobacco Intervention; Addict. Behav. 32 (2007) 187-193.

58. Lawrence, D., A. Rose, P. Fagan, E.T. Moolchan, J.T. Gibson, and C.L. Backinger: National Patterns and Correlates of Mentholated Cigarette Use in the United States; Addiction 105 (S1) (2010) 13-31. DOI: 10.1111/j.1360-0443.2010.03203.X

59. Jones, M.R., B.J. Apelberg, M. Tellez-Plaza, J.M. Samet, and A. Navas-Acien: Menthol Cigarettes, Race/Ethnicity, and Biomarkers of Tobacco Use in U.S. Adults: The 1999-2010 National Health and Nutrition Examination Survey (NHANES); Cancer Epidemiol. Biomarkers Prev. 22 (2013) 224-232.

DOI: 10.1158/1055-9965.EPI-12-0912

60. Hickman, N.J. III, K.L. Delucchi, and J.J. Prochaska: Menthol Use Among Smokers with Psychological Distress: Findings from the 2008 and 2009 National Survey on Drug Use and Health; Tob. Control 23 (2014) 7-13.

DOI: $10.1136 /$ tobaccocontrol-2012-050479

61. Gundersen, D.A., C.D. Delnevo, and O. Wackowski: Exploring the Relationship between Race/Ethnicity, Menthol Smoking, and Cessation, in a Nationally Representative Sample of Adults; Prev. Med. 49 (2009) 553-557. DOI: 10.1016/j.ypmed.2009.10.003

62. Trinidad, D.R., E.J. Pérez-Stable, K. Messer, M.M. White, and J.P. Pierce: Menthol Cigarettes and Smoking Cessation Among Racial/Ethnic Groups in the United States; Addiction 105 (S1) (2010) 84-94. DOI: 10.1111/j.1360-0443.2010.03187.x

63. Levy, D.T., K. Blackman, J. Tauras, F.J. Chaloupka, A.C. Vilanti, R.S. Niaura, D.M. Vallone, and D.B. Abrams: Quit Attempts and Quit Rates Among Menthol and Nonmenthol Smokers in the United States; Am. J. Public Health 101 (2011) 1241-1247. DOI: 10.2105/AJPH.2011.300178

64. Ahluwalia, J.S., K.J. Harris, D. Catley, K.S. Okuyemi, and M.S. Mayo: Sustained-Release Bupropion for Smoking Cessation in African Americans: A Randomized Controlled Trial; JAMA 288 (2002) 468-474. 
65. Ahluwalia, J.S., K. Okuyemi, N. Nollen, W.S. Choi, H. Kaur, K. Pulvers, and M.S. Mayo: The Effects of Nicotine Gum and Counselling Among African American Light Smokers: A 2 x 2 Factorial Design; Addiction 101 (2006) 883-891.

66. Partin, M.R., L.C. An, D.B. Nelson, S. Nugent, A. Snyder, S.S. Fu, M.L. Willenbring, and A.M. Joseph: Randomized Trial of an Intervention to Facilitate Recycling for Relapsed Smokers; Am. J. Prev. Med. 31 (2006) 293-299.

67. Cropsey, K., G. Eldridge, M. Weaver, G. Villalobos, M. Stitzer, and A. Best: Smoking Cessation Intervention for Female Prisoners: Addressing an Urgent Public Health Need; Am. J. Public Health 98 (2008) 1894-1901. DOI: 10.2105/AJPH.2007.128207

68. Cox, L.S., N.L. Nollen, M.S. Mayo, W.S. Choi, B. Faseru, N.L. Benowitz, R.F. Tyndale, K.S. Okuyemi, and J.S. Ahluwalia: Bupropion for Smoking Cessation in African American Light Smokers: A Randomized Controlled Trial; J. Natl. Cancer Inst. 104 (2012)
290-298. DOI: 10.1093/jnci/djr513

69. Piper, M.E., S.S. Smith, T.R. Schlam, M.C. Fiore, D.E. Jorenby, D. Fraser, and T.B. Baker: A Randomized Placebo-Controlled Clinical Trial of 5 Smoking Cessation Pharmacotherapies; Arch. Gen. Psychiatry 66 (2009) 1253-1262.

DOI: $10.1001 /$ archgenpsychiatry.2009.142

Corresponding author:

Rolf Weitkunat

Philip Morris International, Research \& Development, 2000 Neuchâtel, Switzerland

Phone: +4158242 2563. Fax: +41582422811

Email: rolf.weitkunat@pmi.com 


\section{APPENDIX A}

Explanation of choice of TTFC study where more than one study was based on the same data set.

All publications providing data that met the inclusion criterion for the meta-analysis of TTFC for menthol smokers compared to non-menthol smokers are listed in Appendix B. Three publications reported results for the 2003 and 2006/2007 Tobacco Use Supplement to the US Current Population Survey (TUS-CPS). FAGAN et al. (publication 7, Appendix B) (36) reported results for both $\mathrm{TTFC} \leq 5 \mathrm{~min}$ and $\leq 30 \mathrm{~min}$, and their results were adjusted for a large number of covariates. LAWRENCE et al. (publication 9) (58) provided a result for $\leq 30 \mathrm{~min}$. Although their result was adjusted, the adjustment factors were not specified. Lastly, CURTIN et al. (publication 18) (44) reported results for both $\leq 5$ and $\leq 30 \mathrm{~min}$, but their results were unadjusted. As a consequence, the FAGAN et al. results were used in the meta-analysis for both $\leq 5$ and $\leq 30$ min. Lastly, AHIJEVYCH and FORD (publication 8) (37) also reported data from the 2006/7 TUS-CPS, however not from the 2003 survey. Given that data in this publication were analyzed only for subjects between 18 and 24, it was decided to retain this study despite there being some overlap with the FAGAN et al. 2010 study. If there were indeed a difference in TTFC for young smokers between menthol and non-menthol cigarettes, it would not be detectable in the FAGAN et al. results ( $\mathrm{N}=45,315$ subjects) but would be detectable in AHIJEVYCH and FORD ( $\mathrm{N}=3,129$ subjects).

Two studies reported results for data obtained from the National Health and Nutrition Examination Survey (NHANES). JONES et al. (publication 15) (59) reported on TTFC results for $\leq 5 \mathrm{~min}$ from NHANES 2001-2010, while CURTIN et al. (publication 18) (44) reported on results for TTFC ( $\leq 5$ and $\leq 30 \mathrm{~min}$ ) from the same data base. The sample size analyzed by JONES et al. was smaller than that analyzed by CURTIN et al. (2,096 vs. 4,759 subjects). This was probably a result of the fact that the subject of the JONES et al. publication was biomarkers of tobacco use in US adults, and thus it is likely that a sub-sample was used. As a consequence the CURTIN et al. result was used for both the 5 and 30 min time periods. Lastly, two publications were based on data from the National Survey on Drug Use and Health (NSDUH). HICKMAN et al. (publication 14) (60) reported on NSDUH 2008-2009, whereas CURTIN et al. (publication 18) (44) covered the period 2001-2009. The sample sizes reflect this point, 24,157 and 77,183 subjects, respectively. The CURTIN et al. results were not adjusted. Although it is possible that the OR presented by HICKMAN et al. may have been adjusted, this is not certain given that TTFC was only a minor component of the research presented. Therefore, it was decided to use the CURTIN et al. results due to the larger number of subjects.

Having made these selections it was necessary to ensure that these choices did not materially bias the results in the direction of a shorter TTFC for menthol smokers. With respect to the TUS-CPS there are four ORs for FAGAN et al. (36) with TTFC $\leq 5 \mathrm{~min}$ as a function of cigarettes per day (CPD). These range from 0.94-1.22. The OR obtained by CURTIN et al. (44) for TTFC $\leq 5$ min was 0.93 . Therefore, exclusion of CURTIN et al. did not bias the results favorably for menthol smokers. The same is true with respect to the results of the analysis for TTFC $\leq 30 \mathrm{~min}$ reported in FAGAN et al. In this case the ORs, once again reported as a function of cpd, ranged from 0.98 to 1.20 . The OR reported by LAWRENCE et al. (58) was 0.89 , clearly indicating a greater tendency of non-menthol smokers to smoke their first cigarette within 30 minutes after waking, while the OR for CURTIN et al. (44) was 1.12, within the range of ORs reported by FAGAN et al.

With respect to the two overlapping studies for NHANES 2001-2010, CURTIN et al. (44), the selected study, reported an $\mathrm{OR}=1.08(95 \% \mathrm{CI}, 0.95-1.24)$ for $\mathrm{TTFC} \leq 5 \mathrm{~min}$, whereas JONES et al. (59), the excluded study, reported on $\mathrm{OR}=1.13(95 \%$ CI, 0.93-1.37). These two results are not significantly different. Lastly, CURTIN et al. (44) reported an $\mathrm{OR}=1.03(95 \% \mathrm{CI}, 1.00-1.06)$ for $\mathrm{TTFC} \leq 30 \mathrm{~min}$ based on NSDUH data, while the OR reported by HICKMAN et al. (60) was 1.05 (95\% CI, 1.00-1.10). Once again, these two results are not significantly different. 


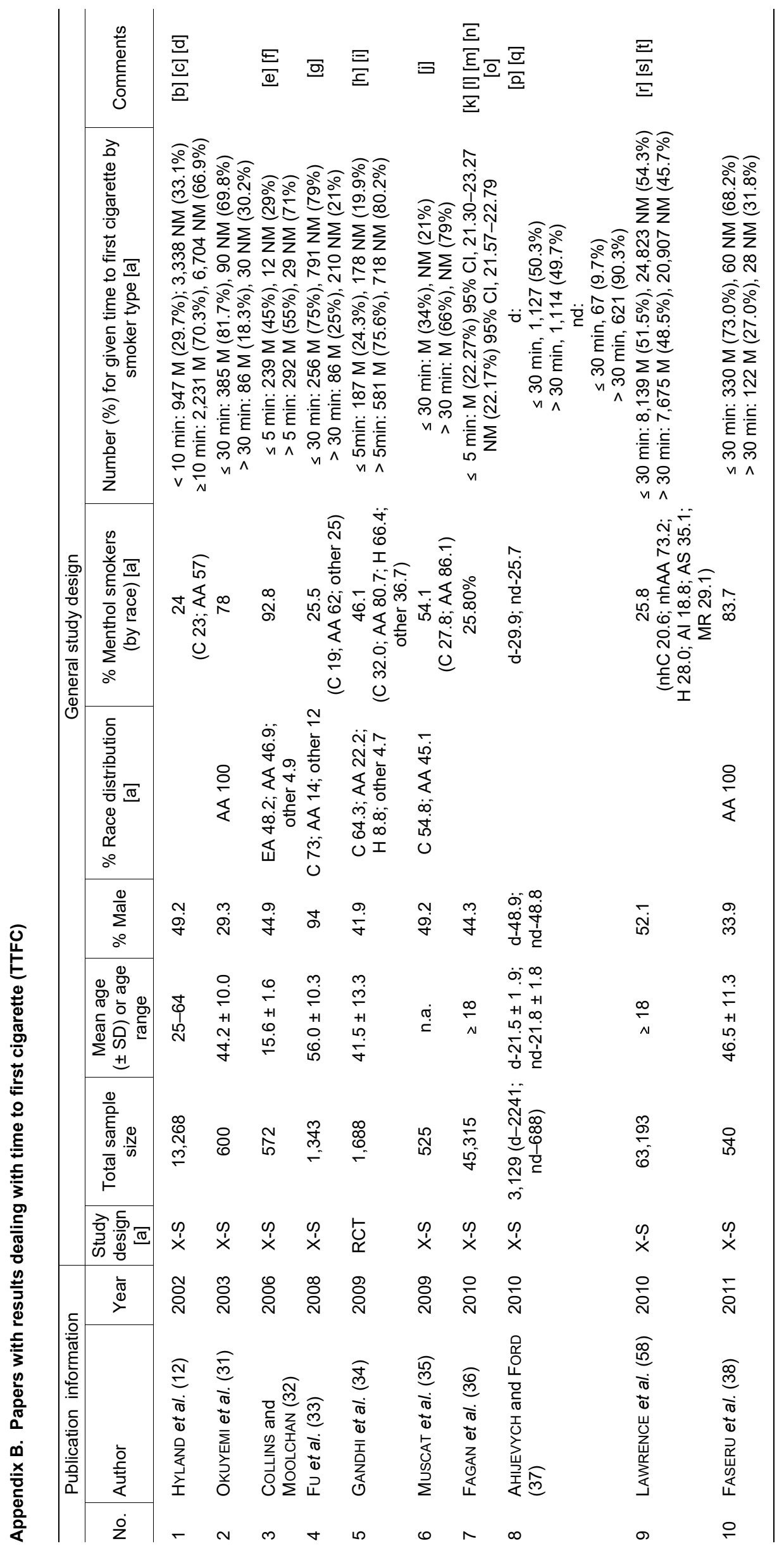




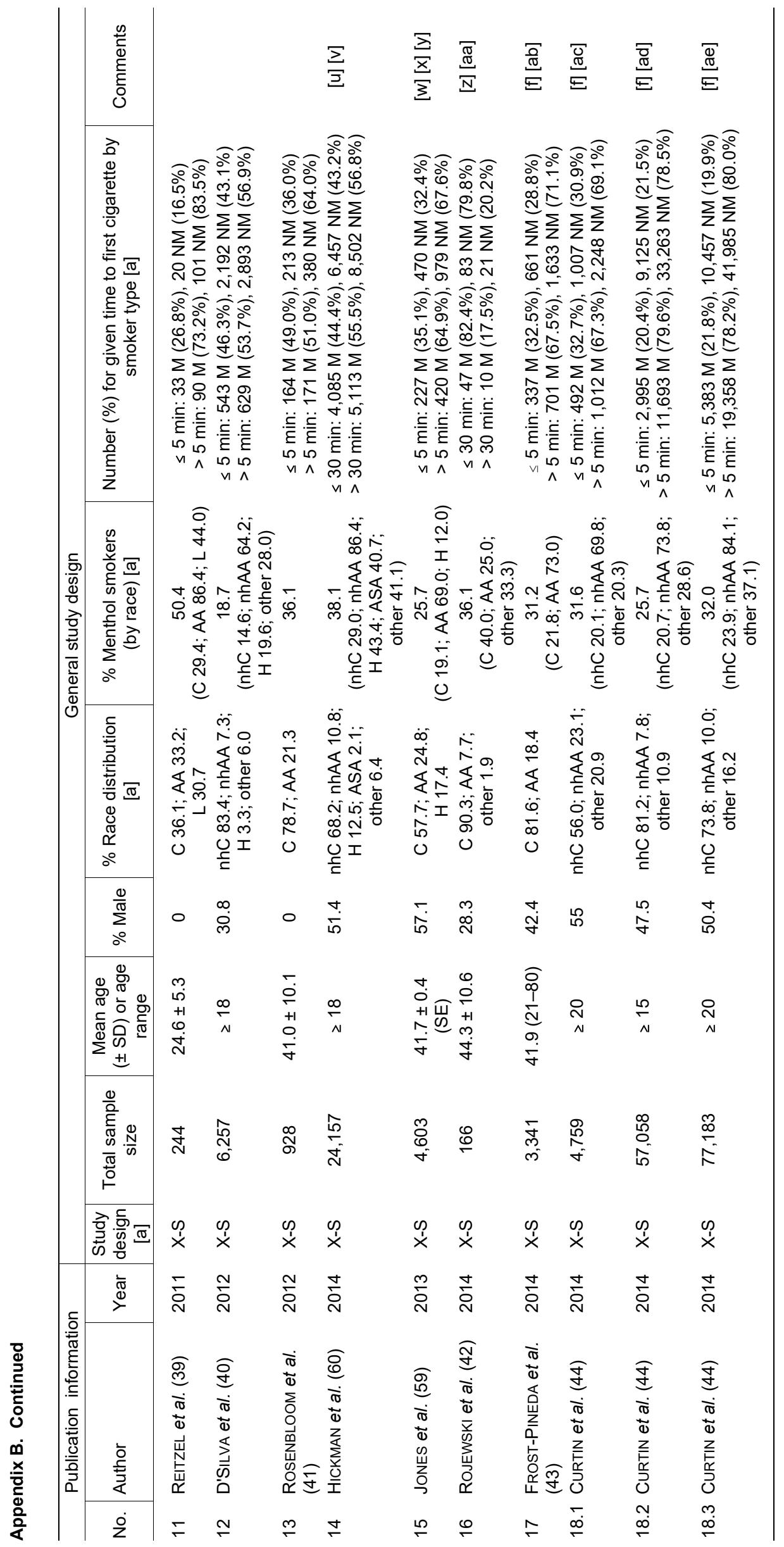




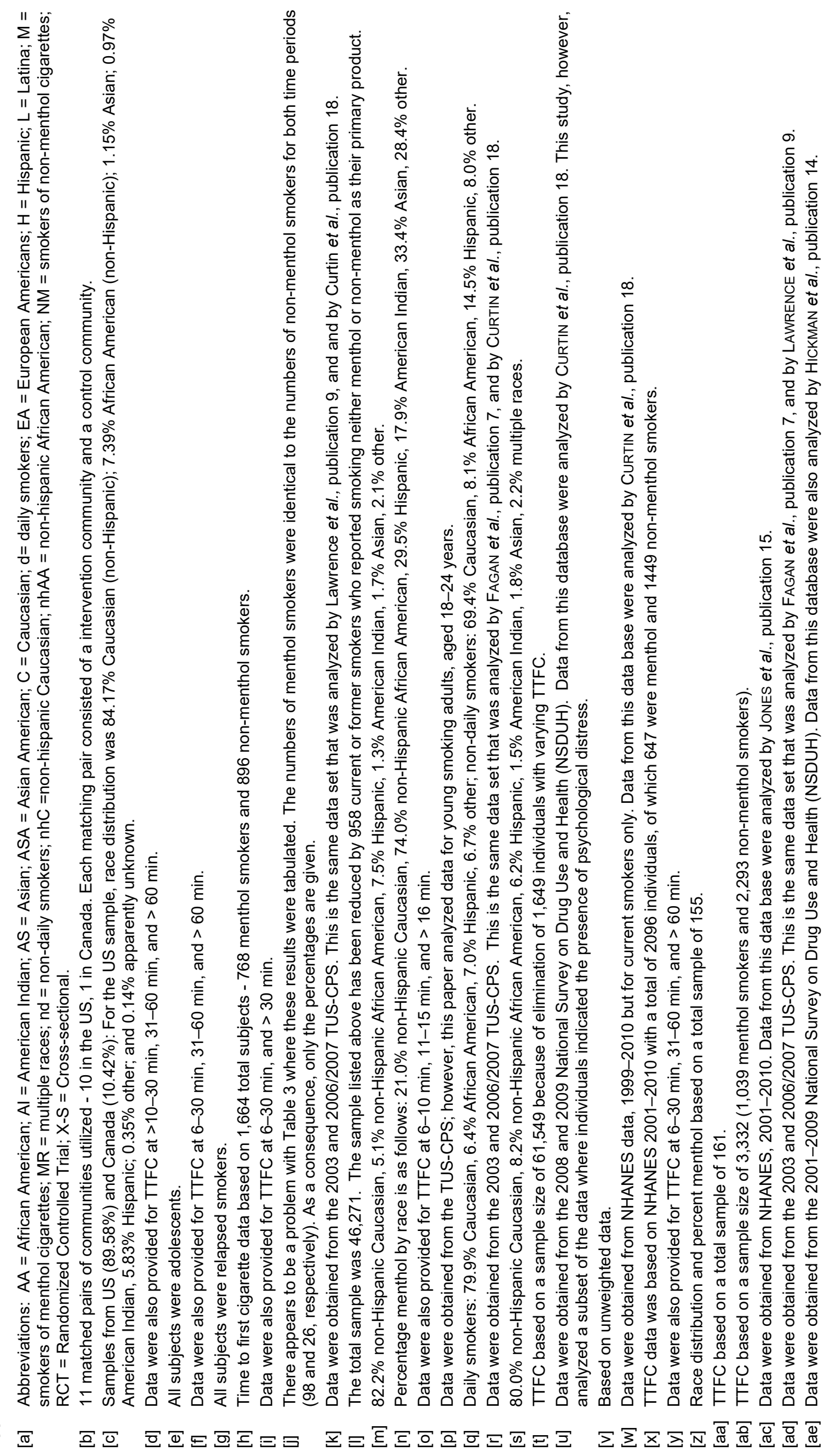




\section{APPENDIX C}

Explanation of choice of cessation study where more than one study was based on the same data set.

All publications providing data that met the inclusion criterion for the meta-analysis of cessation rates for menthol smokers compared to non-menthol smokers are listed in Appendix D. Three publications provided results drawn from the 2005 National Health Interview Survey Cancer Control Supplement (NHIS-CCS); namely, GUNDERSEN et al. (61) (publication 9), STAHRE et al. (50) (publication 13), and SULSKY et al. (13) (publication 27). The STAHRE et al. analysis was based on 12,004 subjects, whereas GUNDERSEN et al. reported data on a much smaller sample size; namely, 7,815 subjects. The primary reason for the difference in sample size is that GUNDERSEN et al. restricted their analysis to current and former smokers who indicated that they had ever attempted to quit smoking. Not only is the STAHRE et al. sample size larger, but applying the restriction used by GUNDERSEN et al. could bias the results. SULSKY et al. analyzed not only the NHIS-CCS 2005 data but also the NHIS-CCS 2010 data. There is, however, a major issue with the SULSKY et al. results in that the sample size was not specified. The only information given was the frequency data for current smokers and former smokers based on the US population. As a consequence, the STAHRE et al. results were chosen for the meta-analysis.

The second set of multiple results drawn from the same database includes four studies that used data from the 2003 and 2006-2007 Tobacco Use Supplement (TUS), a module that is periodically added to the US Current Population Survey (CPS). These four studies were TRINIDAD et al. (62) (publication 12), FAGAN et al. (36) (publication 14), LEVY et al. (63) (publication 16) and DELNEvo et al. (52) (publication 18). The sample sizes for each of these four studies are 73,691, 45,310,65,510, and 65,319 subjects, respectively. The FAGAN et al. sample was considerably smaller than the other three samples; therefore, the results from this publication were not selected for meta-analysis. Although it would appear that TRINIDAD et al. have analyzed the largest sample, this sample size represents only ever smokers who specified either menthol or non-menthol as their usual type of cigarette. The total number of ever smokers was 125,369 . Not only does this sample size appear to be out of line compared to the other three studies, but the number of ever smokers who had no usual type of cigarette, 41,349 , also appears to be out of line. As a consequence, this study was not selected. Both DELNEVO et al. and LEVY et al. have approximately equal sample sizes. However, DELNEvo et al. used five different sample restrictions. One of these, sample restriction 2, eliminated all current and former smokers who reported using other tobacco products. As a consequence, these results refer exclusively to the cessation of cigarette smoking. The LEVY et al. analyses did not make this exclusion. Moreover, the analysis presented only a single estimate; namely for all subjects irrespective of race. Given these considerations, the results of the DELNEVo et al. analysis were used in the meta-analysis.

It is important to evaluate if the choices that were made would have materially changed the results obtained. As noted above, STAHRE et al. (50) (publication 13) was chosen to represent the NHIS-CCS data. Results reported by GUNDERSEN et al. (61) (publication 9) and SULSKY et al. (13) (publication 27) were also based on NHIS-CCS data. The ORs for smoking cessation reported by GUNDERSEN et al. were noticeably higher for all subjects $(\mathrm{OR}=1.14)$, Caucasian subjects $(\mathrm{OR}=1.17)$, and African American subjects $(\mathrm{OR}=0.78)$ compared to those reported by STAHRE et al. (see Table 3). On the other hand, the OR reported by GUNDERSEN et al. for Hispanic subjects $(\mathrm{OR}=0.61)$ was somewhat lower. Likewise, SULSKY et al. also reported higher ORs for both Caucasian regular smokers $(\mathrm{OR}=1.07)$ and African American regular smokers $(\mathrm{OR}=1.12)$. As a consequence, selection of the STAHRE et al. data clearly did not bias the meta-analysis in favor of menthol cigarette smokers finding it easier to quit. The situation is somewhat more complicated for studies based on the 2003 and 2006-2007 TUS-CPS data in that there were four such studies. The estimates used in the meta-analysis were derived from the DELNEVo et al. (52) (publication 18). LEVY et al. (63) (publication 16) provided an OR only for all subjects $(\mathrm{OR}=1.09)$, and this result was larger than that of DELNEVo et al. (see Table 3). FAGAN et al. (36) (publication 14) provided four estimates based on CPD category, and those for all subjects $(1.03,0.97,1.05$, $0.93)$ were all somewhat greater than that provided by DELNEVO et al. The results for TRINIDAD et al. (62) (publication 12) were extremely different from the other three studies based on 2003 and 2006-2007 TUS data. The ORs were 0.28 for Caucasian smokers, 0.23 for African American smokers, and 0.48 for Hispanic smokers. Therefore, as noted above, not only are the number of subjects and the number of smokers designated as having "no usual type" of cigarette widely different from the results presented by the other three study groups that analyzed the 2003 and 2006-2007 TUS-CPS data, but the results are widely different as well. There is no obvious explanation for these differences, but given its inconsistencies with three other studies, it would appear that the decision not to utilize this study to represent the TUS-CPS data is justified. 


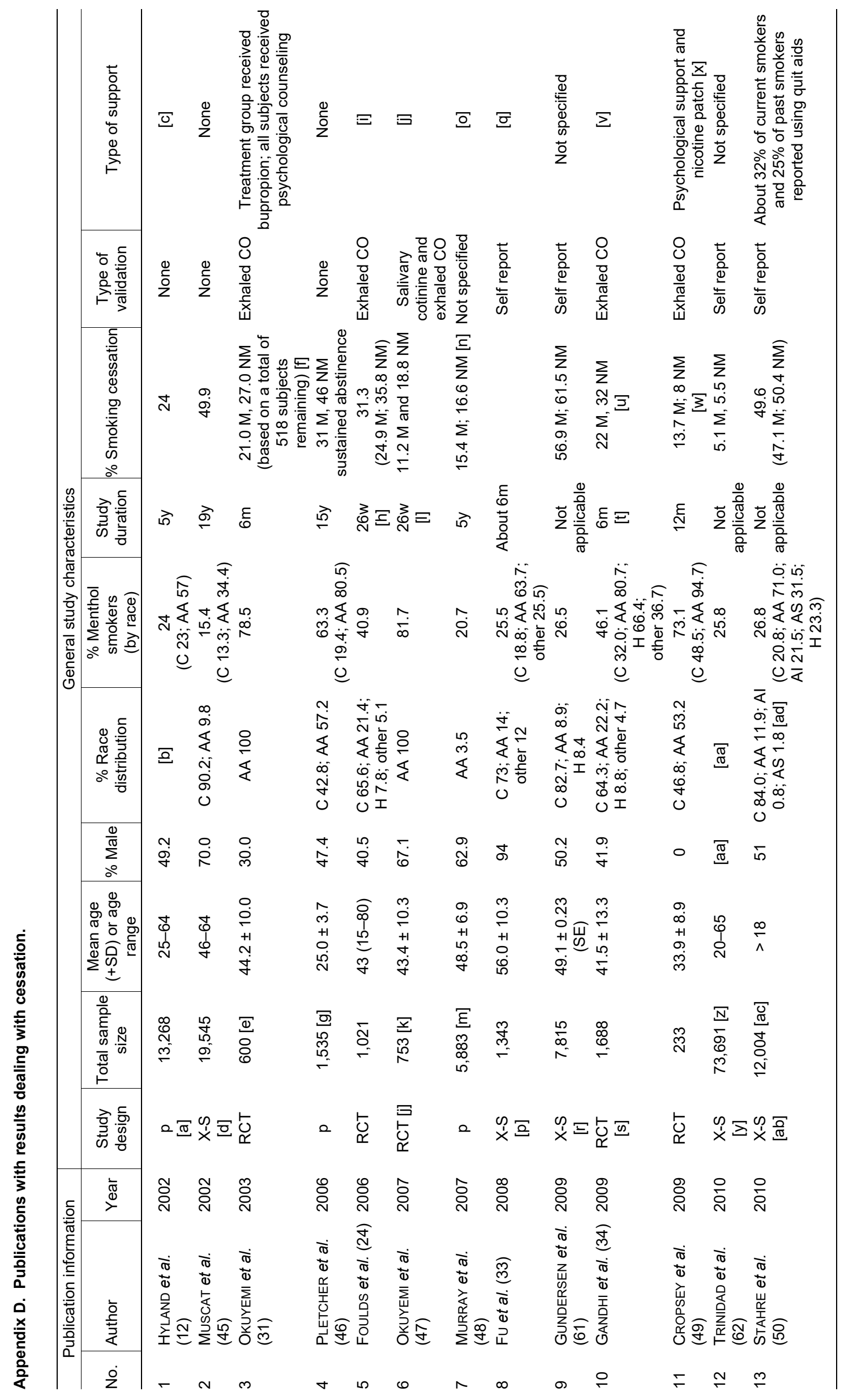




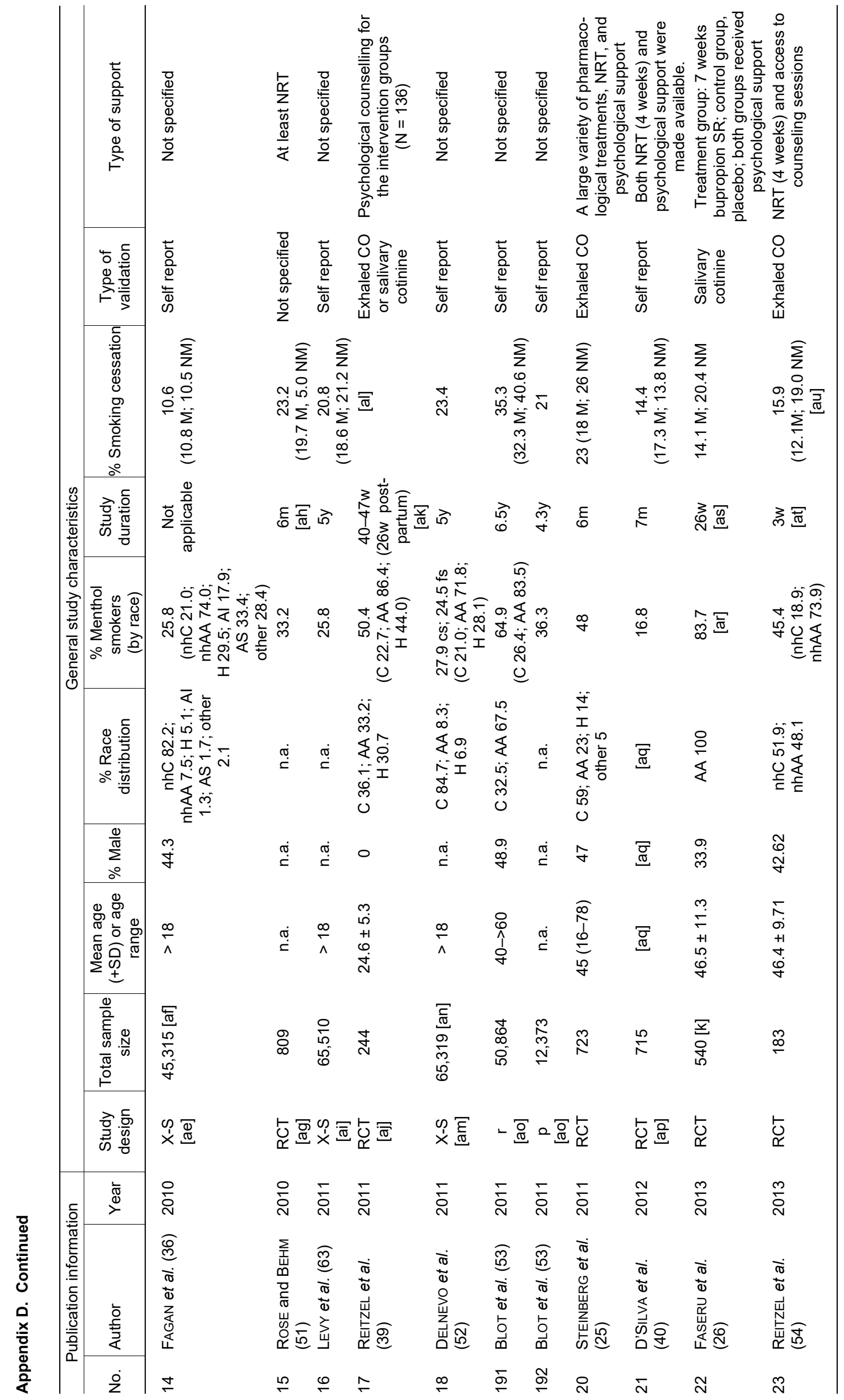




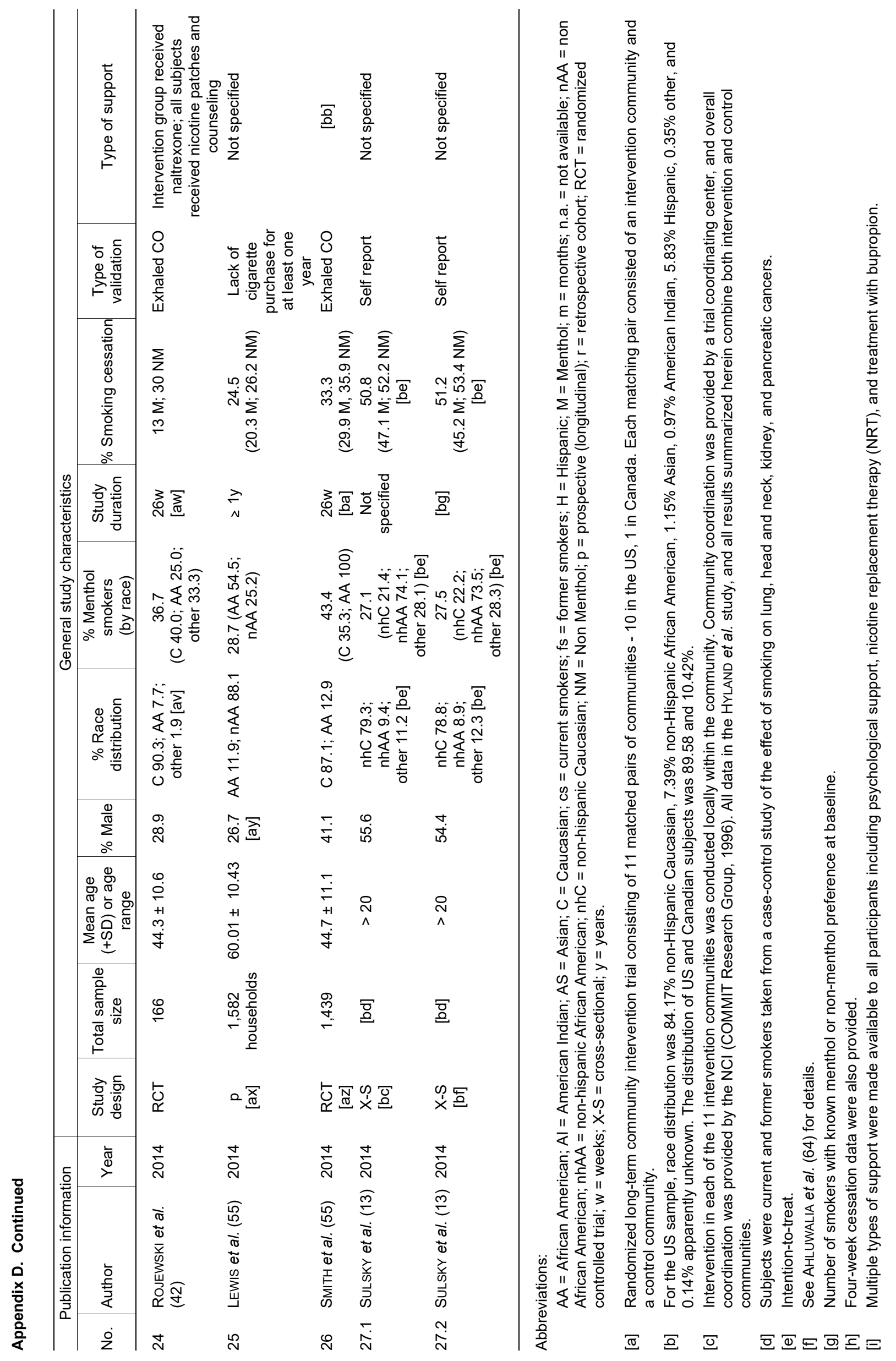




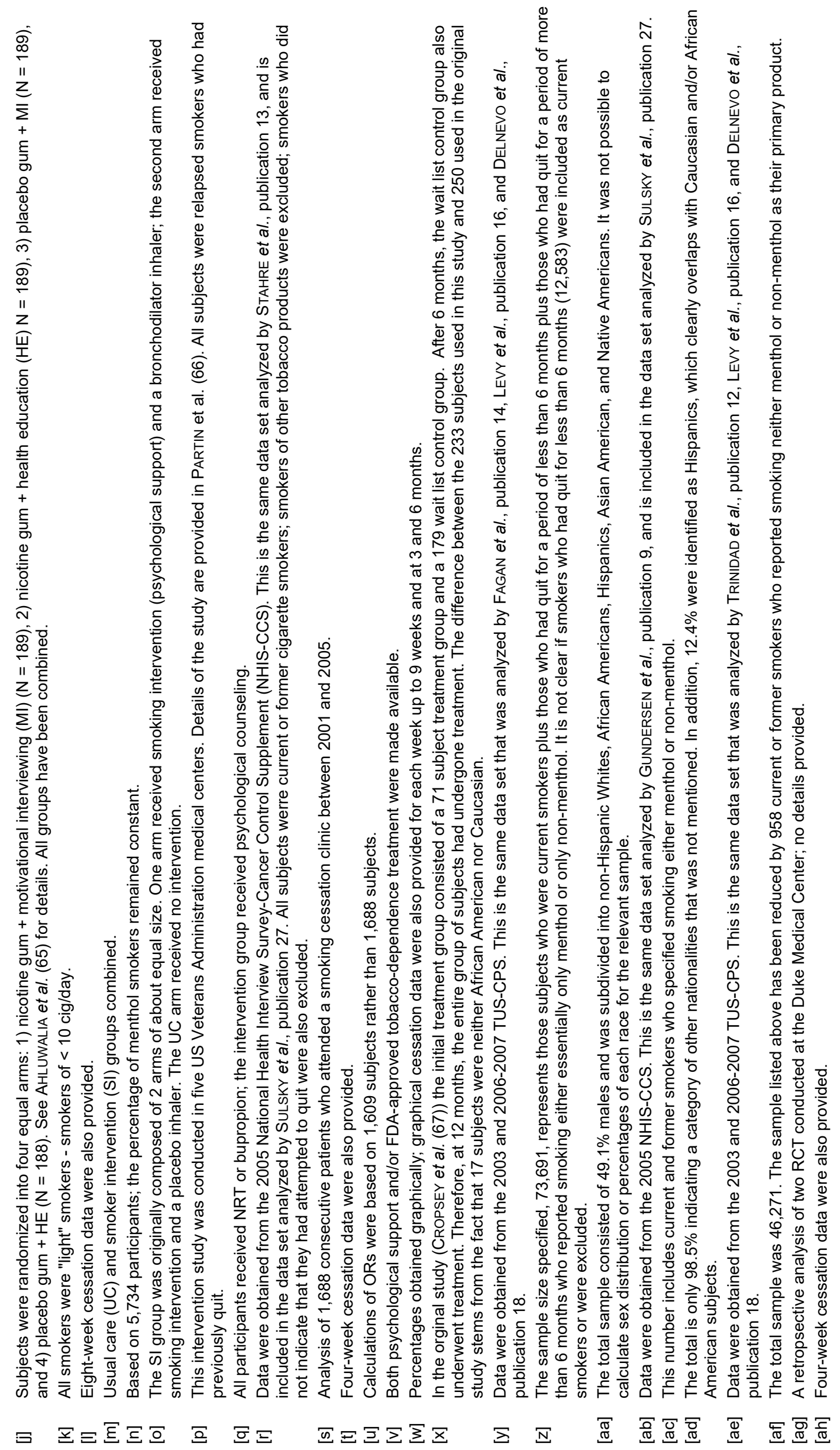




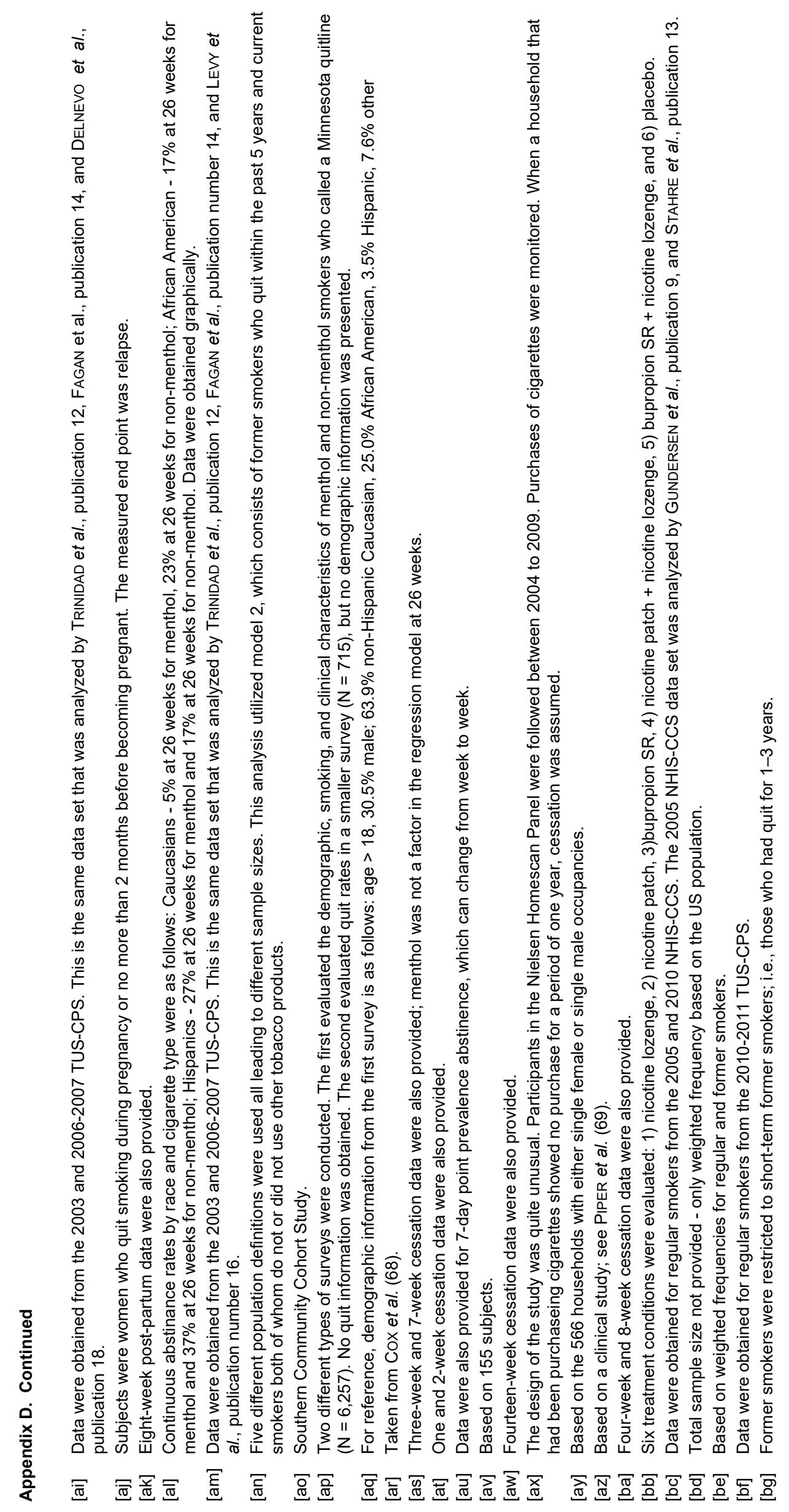




\section{APPENDIX E}

Funnel plots for TTFC point estimates $<5 \min (N=13)$ and cessation point estimates not stratified by race $(N=30)$.

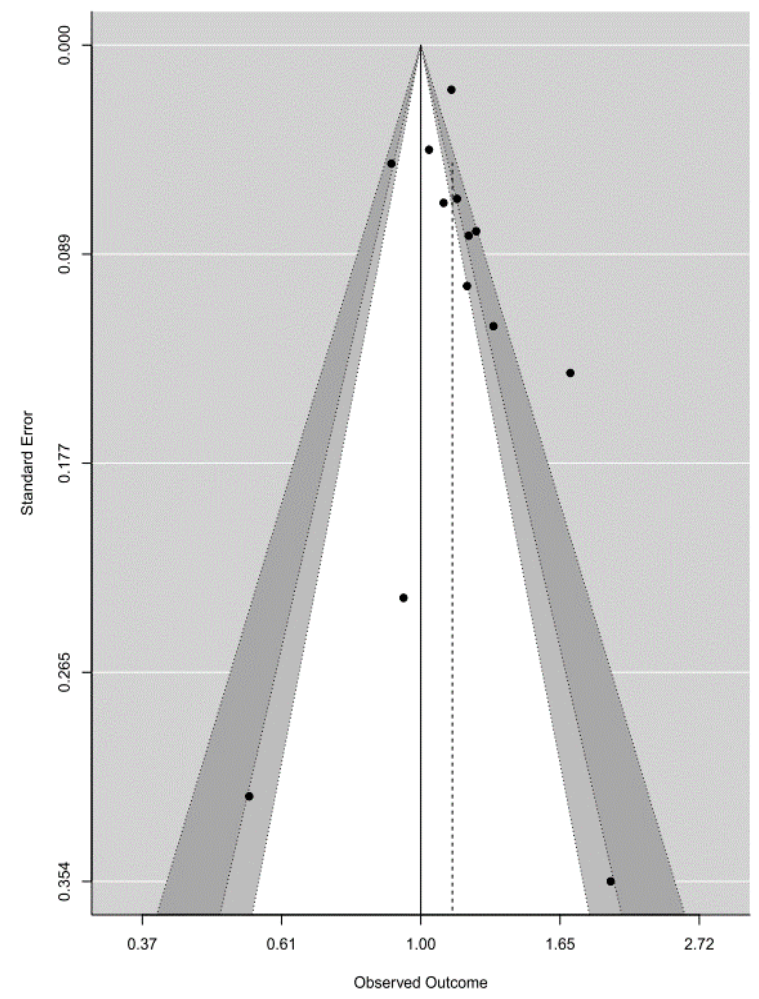

Figure E1. Funnel plot of included point estimates for TTFC $<5 \min (\mathrm{N}=13)$.

There are quite a few studies missing to the left of the point estimate of 1.12 (dashed vertical line), the pooled random-effects meta-analytic result for these estimates. This indicates that the estimate being $>1$ is at least partially due to publication bias in terms of preference to publish studies with OR $>1$. Funnel plot created using R (metafor package).

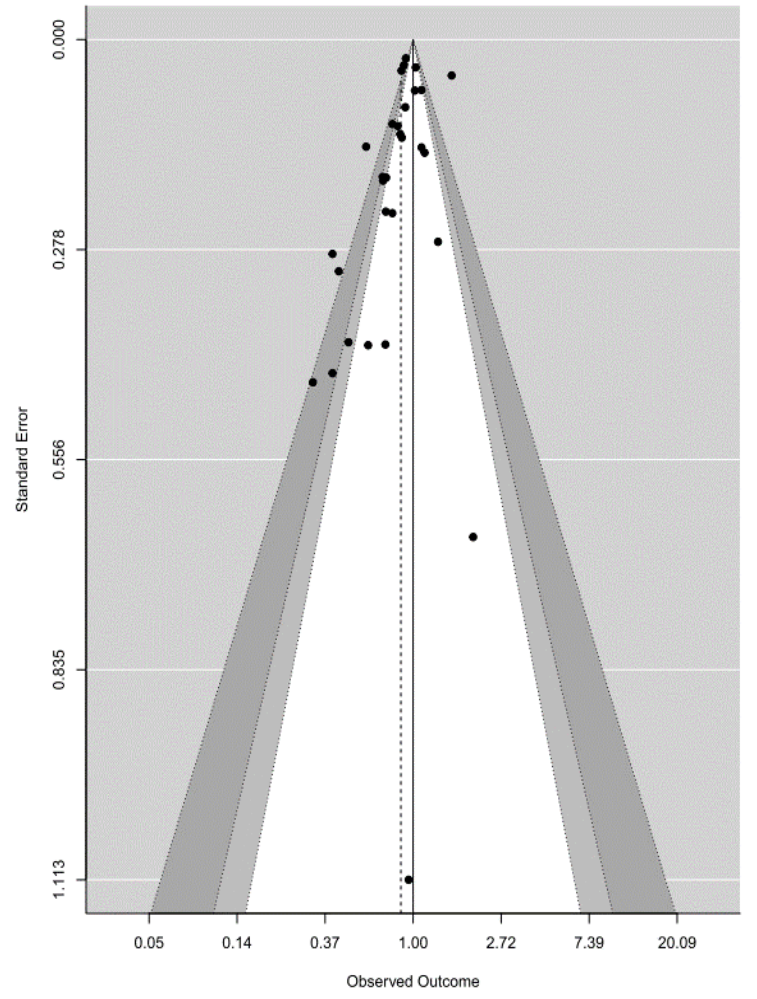

Figure E2. Funnel plot of included point estimates for all included cessation studies not stratified by race $(\mathrm{N}=30)$.

There are quite a few studies missing to the right of the point estimate of 0.87 (dashed vertical line), the pooled random-effects meta-analytic result for these estimates. This indicates that the estimate being $<1$ is very likely at least partially due to publication bias in terms of preference to publish studies with OR $<1$. This appears to be especially true for smaller studies (i.e., larger standard errors). Funnel plot created using R (metafor package). 